\title{
Technical Analysis of the Natural Gas to Hydrocarbon Liquid Process
}

\author{
I. J. Otaraku' ${ }^{1}$ O. A. Vincent ${ }^{2}$ \\ ${ }^{1}$ Department of Chemical Engineering, University of Port Harcourt, Port Harcourt, Nigeria \\ ${ }^{2}$ Centre for Gas Refining and Petrochemicals, Institute of Petroleum Studies, University of Port Harcourt, Port Harcourt, Nigeria
}

Email address:

ipeghan.otaraku@gmail.com (I. J. Otaraku), vincent.agboola@cgrpng.org (O. A. Vincent)

\section{To cite this article:}

I. J. Otaraku, O. A. Vincent. Technical Analysis of the Natural Gas to Hydrocarbon Liquid Process. American Journal of Chemical Engineering. Special Issue: Developments in Petroleum Refining and Petrochemical Sector of the Oil and Gas Industry. Vol. 3, No. 2-1, 2015, pp. 25-40. doi: 10.11648 j.ajche.s.2015030201.14

\begin{abstract}
The technical analysis carried out in this paper is aimed at dealing with element incorporation, structure generation and optimization of the gas-to-liquid (GTL) process. The GTL model developed did not include the desulphurization unit as well as the product upgrading unit. A detailed description of the sequential steps for analyzing the process is as follows: firstly, a base-case process is designed with parameters and operating conditions obtained from literature. Secondly, this flowsheet is simulated with computer-aided simulation package ASPEN Hysys V8.4 to evaluate the specific characteristics of the main equipment and streams entering and leaving units. Thirdly, the simulated base case was analyzed in terms of Thermal Efficiency (TE), Carbon Efficiency (CE) and product flow to upgrading. This process was carried out using the optimizer tool for steady-state modelling to account for multiple variables in the Hysys simulation with the aid of case studies to maximize a given objective function. This resulted in a CE of $82.41 \%$, TE of $65.93 \%$ and a production of $19940 \mathrm{bbl} / \mathrm{d}$ of syncrude.
\end{abstract}

Keywords: Gas-to-Liquid, Optimization, Steady State Modeling, Thermal Efficiency, Carbon Efficiency

\section{Introduction}

The term gas-to-liquid (GTL) is a technology designed to convert natural gas to liquid fuels, as an alternative to the traditional refining of crude oil and other natural gas commercialization routes [1]. These fuels are considered a very clean fuel, with no sulphur content, low aromatics content and lower emissions of hydrocarbons, CO, NOX and particulates upon combustion, when compared to traditional fuels [2].

In addition, GTL diesel has a superior cetane number compared to regular diesel with 70 and 45 respectively [3]. Essentially this means that GTL diesel has a higher energy density and performance than regular diesel [4]. GTL products can be blended with traditional petroleum products making it possible to transport with current technology without the need of special tankers such as liquefied natural gas (LNG) require [5]. Another advantage is its ability to be used in the current market and its infrastructure, supply systems and engines [6].

Consequently, a transition between traditional fuels and GTL fuel could be carried out without extra incurred costs.
This gives it a large advantage compared to other alternative fuels that need different supply systems than those used today. With GTL diesel being blendable with products from crude oil, it also offers a possibility of upgrading low grade conventional diesel and hence an increased utilization of the crude oil based products [5]. GTL fuel hence offers a solution to both the expected fuel switch and the increased environmental concerns.

The main parts of the GTL process can be broken down into four major steps, including: treating of natural gas to remove water and impurities, reforming of the natural gas to produce synthesis gas or syngas ( $\mathrm{CO}$ and $\mathrm{H}_{2}$ mixture), then, Fischer-Tropsch (FT) reaction, which is the heart of GTL technology where, conversion of syngas into chains of hydrocarbon products takes place on a catalyst surface and the final stage is the upgrading of syncrude products through cracking and hydro-processing units to produce variety of fuel fractions and value added chemical $[4,7,8]$.

The GTL process has gained renewed interest as a result of the need for more clean burning fuels, probability of increased oil prices due to reduced crude oil reserves, the potential of monetizing stranded gas and taxes and legislations put on gas flaring [9]. Typical advanced 
commercial FT reactor technology is the Mossgas plant in South Africa, producing Fischer Tropsch products through the high temperature process, came on line in 1992 [10]. In 1993 Shell opened a GTL plant in Bintulu, Malaysia, known as the middle distillate synthesis (SMDS) technology. Similar Fischer-Tropsch reactor (FTR) technology is used in the Pearl project from Shell and Qatar petroleum which is currently the largest GTL project worldwide of capacity reaching $140,000 \mathrm{bbl} / \mathrm{d}[11,12]$. Another big GTL project is the Oryx GTL plant using slurry phase distillate process (SPD), and more recently the Sasol and Chevron Escravos plant in Nigeria which got off ground in 2014 [13].

Although GTL process is already in industrial application it is still challenged by many design and scale up problems, including the high operation cost of large capacity plants [5]. Since the reaction is highly exothermic the system needs lots of heat exchange equipment, and efficient processes to control mass and heat transfer inside the reactor as well [5]. Furthermore, the reactor should stand high pressure required for the FT reaction. The main objective of this paper is to investigate the potentials for optimization of a GTL plant and for this purpose such a plant was modelled and simulated in Hysys. The methodology explained in this paper is based on conventional techniques in addition to a modern approach to simultaneously optimize the process while considering its technical feasibility.

\section{Methodology}

Figure 1 is a representation of a typical process flow diagram of the GTL process. First, treated natural gas is preheated and sent into a pre-reformer to react with steam in order to crack the heavier hydrocarbons in the natural gas before sending it into an autothermal reactor (ATR) for methane to react with oxygen. The temperature of the syngas from the reactor is too high to be fed into the Fisher-Tropsch reactor (FTR). Therefore, the syngas stream is cooled down and water is separated out. The syncrude from the FTR is fed to distillation columns to produce different hydrocarbon fractions which are referred to as GTL products, and the tailgas is introduced through cooling equipment and water separation equipment to final treatment or to recycle.

The design specifications and requirements are discussed in the following sections on the basis of feed, product and operating conditions of the units.

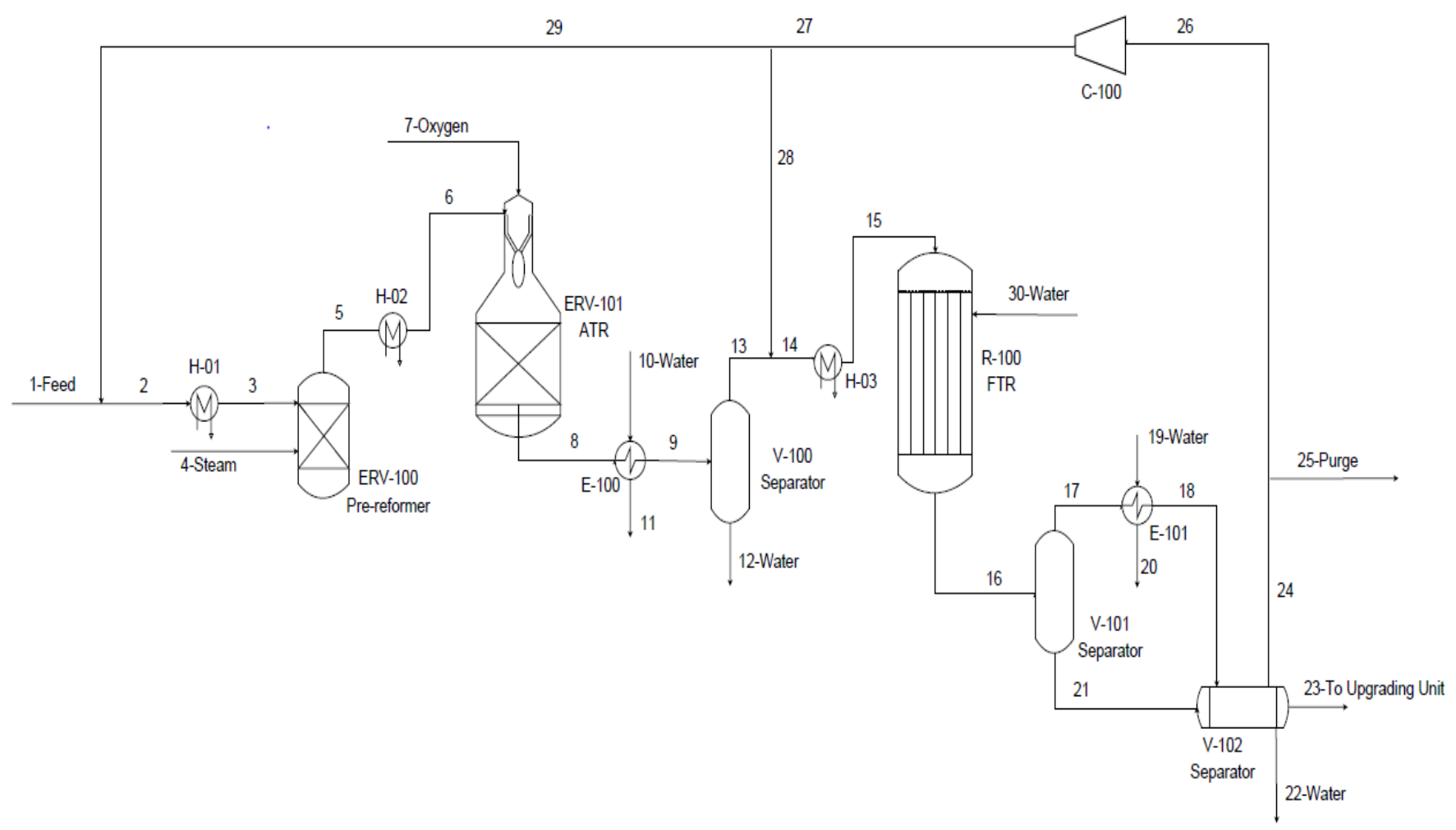

Figure 1. Process flow diagram of a typical GTL plant [14].

\subsection{Modelling Basis and Specifications}

\subsubsection{Modelling Environment}

The GTL plant was modelled steady state in ASPEN Hysys V8.4. In setting up the model, the fluid property package was chosen to be Peng-Robinson and all hydrocarbon components with four or more $\mathrm{C}$-atoms were added as n-type hydrocarbons and $\mathrm{C}_{21 \rightarrow \infty}$ was modelled as $\mathrm{C}_{30}$ due to similarities in their properties. The reactions were added in sets for the three main units operations, Pre-reformer, ATR and FT-reactor respectively.

\subsubsection{Feed Conditions and Specifications}

The molar flow of the various feed and other input values used for modelling the GTL plant are given in Table 1. They are based on values given in an article on GTL optimization by 
Panahi et al [4].

Table 1. Molar flow and inlet conditions for the feed chosen for modelling of the GTL plant [4].

\begin{tabular}{llll}
\hline Input & $\mathbf{T}\left({ }^{\mathbf{O}} \mathbf{C}\right)$ & Pressure $(\mathbf{k P a})$ & Molar flow $(\mathbf{k m o l} / \mathbf{h})$ \\
\hline Natural gas & 40 & 3000 & 8195 \\
Steam & 252 & 4045 & 5204 \\
Oxygen & 200 & 3000 & 5236 \\
\hline
\end{tabular}

\subsubsection{Conditions of the Main Units}

The reforming technology was chosen to be the one proposed by Haldor Topsøe, only omitting the desulphurization unit. In this model, the natural gas was heated from the inlet temperature of $40^{\circ} \mathrm{C}$ to $455^{\circ} \mathrm{C}$, as is in the common range for the inlet temperature of the pre-reformer [15]. The steam stream was modelled to enter at $252^{\circ} \mathrm{C}$.

The pre-reformer was simulated as an equilibrium reactor and the reactions as an equilibrium set. The temperature and pressure were set at $530^{\circ} \mathrm{C}$ and $3000 \mathrm{kPa}$ respectively. Table 2 shows the reactions modelled and their respective enthalpy of reaction.

Table 2. Overview of the reactions modelled in the pre-reformer and their corresponding enthalpy of reaction [16]

\begin{tabular}{ll}
\hline Reaction & $\Delta_{\boldsymbol{r x n}} \boldsymbol{H}_{\mathbf{2 9 8}}^{\boldsymbol{o}}\left[\frac{\boldsymbol{k J}}{\boldsymbol{m o l}}\right]$ \\
\hline $\mathrm{C}_{2} \mathrm{H}_{6}+2 \mathrm{H}_{2} \mathrm{O} \leftrightarrow 5 \mathrm{H}_{2}+2 \mathrm{CO}$ & 350 \\
$\mathrm{C}_{3} \mathrm{H}_{8}+3 \mathrm{H}_{2} \mathrm{O} \leftrightarrow 7 \mathrm{H}_{2}+3 \mathrm{CO}$ & 500 \\
$\mathrm{C}_{4} \mathrm{H}_{10}+4 \mathrm{H}_{2} \mathrm{O} \leftrightarrow 9 \mathrm{H}_{2}+4 \mathrm{CO}$ & 650 \\
$\mathrm{CO}+3 \mathrm{H}_{2} \leftrightarrow \mathrm{CH}_{4}+\mathrm{H}_{2} \mathrm{O}$ & -210 \\
$\mathrm{CO}+\mathrm{H}_{2} \mathrm{O} \leftrightarrow \mathrm{CO}_{2}+\mathrm{H}_{2}$ & -41 \\
\hline
\end{tabular}

The reactions in the ATR were taken to be in equilibrium due to the high outlet temperature and hence the ATR was modeled as an equilibrium reactor. The reaction set was consequently also modeled as equilibrium reactions and Table 3 shows the equations modeled and their corresponding reaction enthalpies.

Table 3. Overview of the reactions modelled in the ATR and their corresponding enthalpy of reaction [16].

\begin{tabular}{ll}
\hline Reaction & $\Delta_{\boldsymbol{r x n}} \boldsymbol{H}_{\mathbf{2 9 8}}^{\boldsymbol{o}}\left[\frac{\boldsymbol{k J}}{\boldsymbol{m o l}}\right]$ \\
\hline $\mathrm{CH}_{4}+1.5 \mathrm{O}_{2} \leftrightarrow \mathrm{CO}+2 \mathrm{H}_{2} \mathrm{O}$ & -520 \\
$\mathrm{CH}_{4}+\mathrm{H}_{2} \mathrm{O} \leftrightarrow \mathrm{CO}+3 \mathrm{H}_{2}$ & 210 \\
$\mathrm{CO}+\mathrm{H}_{2} \mathrm{O} \leftrightarrow \mathrm{CO}_{2}+\mathrm{H}_{2}$ & -41 \\
\hline
\end{tabular}

In addition, because the reactions in the ATR are very exothermic and results in an increase in temperature for the produced syngas an upper limit of $1030^{\circ} \mathrm{C}$ was thus set to assure soot free operation.

A heat exchanger was connected downstream of the ATR to bring the temperature of the syngas down to $38^{\mathrm{O}} \mathrm{C}$ so that the steam generated in the ATR is converted to water that can be separated out before the FT-reaction, reducing the volume flow and hence the reactor size. However, $38^{\circ} \mathrm{C}$ is a temperature too low for the low temperature Fischer Tropsch (LTFT) process which runs at $200-240^{\circ} \mathrm{C}$ and hence a heater was included in the model heating up the FTR inlet to $210^{\circ} \mathrm{C}$.

The FTR was modeled as a plug flow reactor (PFR) as this being the flow pattern that mostly resembles a multi tubular fixed bed (MTFB) reactor and a starting volume of $1000 \mathrm{~m}^{3}$ was chosen. The FT reaction set was defined as kinetic and it included both the FT reaction and the methanation reaction. The stoichiometric coefficients for the FT reactions are modelled based on the ASF-distribution and the kinetics was implemented by the use of Iglesias rate of reactions.

For the FT reaction, only paraffins were considered in this work and the value of $\alpha$ was assumed to be 0.9 . This gives a hydrogen usage ratio of 2.1 as given by Equation 1 [17]. All of the components with carbon number below 21 was modelled as individual units, while the components with carbon number from 21-30 was lumped in a component designated $C_{21+}$. The stoichiometric coefficients were calculated after Equation 2 and 3 as outlined in a paper by Hillestad and Appendix A shows the resulting values [17].

The modelled reactions are given in Table 4, but the FT reaction has been simplified and can be found fully expanded in Appendix A.

$$
\begin{aligned}
& \mathrm{U}=3-\alpha \\
& r_{F T}=(1-\alpha)^{2} \alpha^{(\mathrm{i}-1)} \quad \text { for } \mathrm{C}_{\mathrm{i}}, \mathrm{i}=1, \ldots 20 \\
& r_{F T}=(1-\alpha) \alpha^{20} \quad \text { for } \mathrm{C}_{21 \rightarrow \infty}
\end{aligned}
$$

The Iglesias rate expressions in the form needed in Hysys is given in Equation 4 and 5 while the values for $\mathrm{A}, \mathrm{E}, \mathrm{n}$ and the various component exponents for the respective equations is given in Table 5.

Table 4. Overview of the reactions modelled in the FTR and their corresponding enthalpy of reaction [16].

\begin{tabular}{ll}
\hline Reaction & $\Delta_{\boldsymbol{r x \boldsymbol { n }}} \boldsymbol{H}_{\mathbf{2 9 8}}^{\boldsymbol{o}}\left[\frac{\boldsymbol{k J}}{\boldsymbol{m o l}}\right]$ \\
\hline $\mathrm{CO}+2.1 \mathrm{H}_{2} \rightarrow \sum_{i=1}^{20}(\text { ASF coefficient })_{i} C_{i} \mathrm{H}_{2 i+2}+(\text { ASF coefficient })_{30} \mathrm{C}_{30} \mathrm{H}_{62}+\mathrm{H}_{2} \mathrm{O}$ & -160 \\
$\mathrm{CO}+3 \mathrm{H}_{2} \leftrightarrow \mathrm{CH}_{4}+\mathrm{H}_{2} \mathrm{O}$ & -210 \\
\hline
\end{tabular}

$$
r_{\mathrm{CH}_{4}=k_{1} P \mathrm{P}_{2} P_{C O}^{0.05} / 1+\left(K_{1} \mathrm{PCO}\right)}
$$

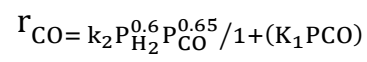


Table 5. Parameters used for kinetic rate expression in Hysys for modeling of the FT reactions [17].

\begin{tabular}{|c|c|c|c|c|c|c|}
\hline \multirow{2}{*}{ Reaction } & \multirow{2}{*}{$\mathbf{A}$} & \multirow{2}{*}{$-\mathbf{E}$} & \multirow{2}{*}{ exponent $\mathrm{PH}_{2}$} & \multicolumn{2}{|c|}{ exponent PCO } & \multirow{2}{*}{$\mathbf{n}$} \\
\hline & & & & numerator & denominator & \\
\hline \multicolumn{7}{|l|}{$r_{C_{4}}$} \\
\hline $\mathrm{k} 1$ & $8.8 \cdot 10^{-6}$ & 37326 & 1 & 0.05 & - & - \\
\hline K1 & $1.096 \cdot 10^{-12}$ & -68401.5 & - & - & 1 & 1 \\
\hline \multicolumn{7}{|l|}{$r_{C O}$} \\
\hline k2 & $1.6 \cdot 10^{-5}$ & 37326 & 0.6 & 0.65 & - & - \\
\hline K1 & $1.096 \cdot 10^{-12}$ & -68401.5 & - & - & 1 & 1 \\
\hline
\end{tabular}

Furthermore, in order to control the reactor temperature water at $220^{\circ} \mathrm{C}$ was chosen as the cooling medium in keeping a constant temperature of the reactor and while in a MTFB reactor, gas and liquid products are separated inside the reactor by gas leaving at the top and liquid products trickling down and exiting the bottom. When using a PFR in Hysys it is only possible with one exit stream and hence to achieve this in the model a separator is modeled separately after the reactor.

The gaseous products are cooled by heat exchanging with water to $38^{\mathrm{O}} \mathrm{C}$ before entering the 3 -way separator together with the liquid products. This was done to separate out water that left the reactor as steam. This will eliminate unnecessary recycling and water being sent to product upgrading.

In the 3-way separator more water is separated out, liquid products are sent to upgrading unit and the remaining gases is split in a purge and a recycle stream. For the base case this split fraction was set to 0.2 to purge and 0.8 in recycle. The recycle stream needs to be compressed before it is further split into two, one back to the FTR while the other is recycled back and mixed with fresh feed. The split ratio was set to be 0.768 and 0.232 respectively. With recycling, the flow sheet is looped and in Hysys this requires one or more recycle blocks for the iteration to be successful.

\subsection{Optimization Procedure}

The optimization procedure for the model was divided into two main parts. First the base case (initial model) was analyzed in terms of performance and secondly in terms of TE, $\mathrm{CE}$, and product flow to upgrading unit. This process was carried out with the use of case studies and optimizer in Hysys

\subsubsection{Case Studies}

Based on the evaluation of the base case, a range of case studies were executed to reveal the interrelations of the process and to locate optimum values. The case studies conducted are as follows:

\section{(i) Case 1 - FTR Volume}

It was indicated in the base case evaluation that the reactions in the FTR did not proceed to the degree that was desired and that this likely was due to a too small reactor. This prompted a case study for the molar flow of $\mathrm{CO}$ and $\mathrm{H}_{2}$ as a function of reactor volume to locate the volume that would give an optimal consumption of reactants and hence amount of product. The case study used reactor volumes between $400-2400 \mathrm{~m}^{3}$.

\section{(ii) Case 2 - Molar Flow of Oxygen}

The exothermic oxidation reaction in the reformer converts methane to water and $\mathrm{CO}$, and provides necessary heat for the steam methane reforming reaction. It is naturally desirable to convert as much methane as possible into syngas to increase the output of products and thus a large oxygen flow seems beneficial. However, the increase in temperature accompanied by the increase in reaction extent for the oxidation reaction must comply with the upper temperature limit of $1030^{\circ} \mathrm{C}$, hence imposing an upper limit for molar flow of oxygen as well. Nevertheless, the produced water from the oxidation reaction might also push the shift reaction to the right consuming $\mathrm{CO}$ and produce $\mathrm{H}_{2}$ and consequently alter the $\mathrm{H}_{2} / \mathrm{CO}$ ratio. This makes it difficult to predict how the addition of oxygen will affect the $\mathrm{H}_{2} / \mathrm{CO}$ ratio. A case study for the molar flow of oxygen and $\mathrm{H}_{2} / \mathrm{CO}$ ratio and also for the molar flow of oxygen and syngas temperature were hence conducted to find an optimal molar flow of oxygen and to highlight the correlation between the parameters. The case study used molar flow of oxygen in the range $3000-7000 \mathrm{kmol} / \mathrm{h}$.

\section{(iii) Case 3 - Molar Flow of Steam}

The molar flow of steam affects not only the $\mathrm{H}_{2} / \mathrm{CO}$ ratio, but also the temperature leaving the ATR and considering that both the molar flow of oxygen and steam affects the temperature, a case study was conducted with the temperature as a function of both of these.

\section{(iv) Case 4 - Recycle Fraction to FTR}

So far the recycle split fraction between the FTR and feed has been kept constant at 0.765 . It might however be more beneficial with another fraction depending on the composition of the recycled stream.

Initially, a case study for the molar flow to upgrading unit as a function of the recycle ratio back to the FTR was conducted but while this indicated that a recycle ratio of 0.85 would give the maximum product flow rate it however gave a syngas temperature of $1056^{\circ} \mathrm{C}$ which was above the constraint from a material aspect and hence this process is not an option. Hence, a case study investigating the effect of recycle ratio to FTR on temperature was consequently conducted to find the highest possible ratio. 


\section{(v) Case $5-\mathrm{H}_{2} / \mathrm{CO}$ Ratio of 2.15}

Even though the case with a recycle ratio of 0.85 gave a too high temperature out of the ATR, it had a larger molar flow of products and a much higher $\mathrm{H}_{2} / \mathrm{CO}$ ratio than previous case studies and hence it was tried to achieve a ratio of approximately 2.15 while keeping the temperature below $1030^{\circ} \mathrm{C}$, to see if this was the reason for the increased the output. This was tried achieved by altering the steam flow rate.

\section{(vi) Case 6 - Steam and Flow to Upgrading}

The increased flow to the upgrading unit as experienced from the previous case study was desirable and to establish if it could further be improved a new case study was conducted. Both the $\mathrm{H}_{2} / \mathrm{CO}$ ratio and molar flow to upgrading unit are dependent variables an independent variable was needed to investigate this relationship. This variable was chosen to be steam as this is the main variable affecting the $\mathrm{H}_{2} / \mathrm{CO}$ ratio. Hence the case study was conducted to outline how the molar flow to upgrading and temperature behaved by varying the steam added.

\section{(vii) Case 7 - Multi Variable}

The previous case studies illustrated the intertwine relationship between oxygen, steam, syngas temperature and $\mathrm{H}_{2} / \mathrm{CO}$ ratio. As a tuning of one and one parameter seemed to be time consuming and inefficient, a multivariable case study was conducted. This was achieved by plotting molar flow of steam and oxygen against molar flow to product upgrading unit. The case study function in Hysys has a limitation of four variables per case study and three variables for the plot and hence the temperature was omitted from this first multi variable analysis.

In addition to this, a new case study called Case 7-adjust which implemented an adjust block to the simulation whilst keeping the temperature of the syngas at $1030^{\circ} \mathrm{C}$ and adjusting the molar flow of oxygen was equally implemented.

\section{(viii) Case 8 - FTR Volume Revisited}

From an article on steady state simulation and optimal operation of a GTL plant by [16], it was stated that a reactor volume over $2200 \mathrm{~m}^{3}$ did not give any significant increase in the liquid production [16]. As the reactor volume applied in this simulation was at $1600 \mathrm{~m}^{3}$ it was desired to see if an increase in volume would positively affect the production. Hence, a new case study was carried out by increasing the reactor volume beyond the value previously found in case 1 . The objective function was changed from maximizing product flow to maximizing the carbon efficiency. It was run four times and the CE base case used as basis was Case 11 from the product flow optimization. The change between each run is only related to numerical values such as tolerance, maximum number of iterations etc. and is outlined in Table 3.

\subsubsection{Optimizer}

Due to the struggle with optimization of the process manually and with the aid of case studies, the optimizer was applied to the simulation. The adjustable variables used in the optimizer are listed in Table 6 together with their starting upper and lower bounds. Two constraints were applied for all simulations. First, the $\mathrm{H}_{2} / \mathrm{CO}$ ratio was set to be above 2 at all times and second; the syngas temperature was set to be below $1031^{\circ} \mathrm{C}$.

Table 6. List of the variables to be adjusted in the optimizer tool in Hysys along with the respective upper and lower bounds

\begin{tabular}{lll}
\hline \multirow{2}{*}{ Reaction } & Range \\
\cline { 2 - 3 } & Minimum & Maximum \\
\hline Reactor volume $\left(\mathrm{m}^{3}\right)$ & 500 & 2300 \\
Molar flow of oxygen $(\mathrm{kmol} / \mathrm{h})$ & 3700 & 5500 \\
Molar flow steam $(\mathrm{kmol} / \mathrm{h})$ & 4500 & 7500 \\
Recycle ration to FTR & 0.0 & 1.0 \\
Purge split & 0.0 & 1.0 \\
\hline
\end{tabular}

\section{(i) Product Flow Optimization}

The objective function was set to maximize the molar flow to the upgrading unit. In total 11 attempts were made at the optimizer for the optimization of product flow and the product flow base case used as basis was Case 8 from the case study optimization. Table 7 outlines the changes made with relations to the previous run.

Table 7. Optimizer changes in Hysys when flow to the upgrading unit was used as objective function.

\begin{tabular}{ll}
\hline Case & Change from previous \\
\hline $\begin{array}{l}\text { Optimizer } \\
\text { base case }\end{array}$ & Based on case 8 from the case study optimization \\
1 & Number of iterations set to 100, tolerance set to 0.001 \\
2 & Tolerance set to 0.01 \\
3 & Re-run \\
4 & Objective function changed to liquid volume flow at \\
& standard conditions \\
5 & Number of iterations set to 200 , tolerance set to $1 \mathrm{E}-5$, \\
6 & maximum change per iteration set to 0.1 \\
7 & Increased number of iterations and function evaluations to \\
8 & 500, lower bound reactor volume set to 1500 \\
9 & Re-run \\
10 & Included temperature of boiling water to FTR in variables \\
11 & Adjust not solved, however T=1030 ${ }^{\circ} \mathrm{C}$ \\
\hline
\end{tabular}

\section{(ii) Carbon Efficiency (CE) Optimization}

The objective function was changed from maximizing product flow to maximizing the carbon efficiency. It was run four times and the CE base case used as basis was Case 11 from the product flow optimization. The change between each run is only related to numerical values such as tolerance, maximum number of iterations etc. and is outlined in Table 8 .

Table 8. Optimizer changes in Hysys when carbon efficiency was used as objective function.

\begin{tabular}{ll}
\hline Case & Change from previous \\
\hline CE base case & $\begin{array}{l}\text { Based on case 11 from the product flow optimizer } \\
\text { Tolerance set to 1E-5, maximum change per iteration set } \\
\text { to } 0.05\end{array}$ \\
ME 2 & $\begin{array}{l}\text { Maximum iterations and function evaluations set to } \\
\text { CE 3 }\end{array}$ \\
CE 4 & $\begin{array}{l}\text { Tolerance set to 1E-6, maximum change per iteration set } \\
\text { to } 0.3\end{array}$ \\
\hline
\end{tabular}




\section{(iii) Thermal Efficiency (TE) Optimization}

The objective function was changed from carbon efficiency to thermal efficiency to see if it changed the optimum. It was run eight times and new bounds as given in
Table 9 and a higher penalty value to keep the $\mathrm{H} 2 / \mathrm{CO}$ ratio above 2 was applied to the CE4 optimization to give a base case for TE optimization. Table 10 outlines the main changes made with relations to previous run.

Table 9. Overview of the optimization variables used by Optimizer for TE in Hysys and their bounds applied for the respective simulations.

\begin{tabular}{|c|c|c|c|c|c|c|c|c|}
\hline \multirow{3}{*}{ Variable } & \multicolumn{2}{|c|}{ TE base case } & \multicolumn{2}{|l|}{ TE 2} & \multicolumn{2}{|l|}{ TE 5} & \multicolumn{2}{|l|}{ TE 8} \\
\hline & \multicolumn{2}{|c|}{ Range } & \multicolumn{2}{|c|}{ Range } & \multicolumn{2}{|c|}{ Range } & \multicolumn{2}{|c|}{ Range } \\
\hline & Min & $\operatorname{Max}$ & Min & $\operatorname{Max}$ & Min & $\operatorname{Max}$ & Min & Max \\
\hline Reactor volume $\left(\mathrm{m}^{3}\right)$ & 1500 & 2300 & 1500 & 2300 & 1500 & 2300 & 1100 & 2200 \\
\hline Molar flow oxygen $(\mathrm{kmol} / \mathrm{h})$ & 4400 & 5700 & 3500 & 5700 & 3000 & 5700 & 3000 & 5700 \\
\hline Molar flow steam $(\mathrm{kmol} / \mathrm{h})$ & 5500 & 9000 & 4500 & 9000 & 6500 & 11000 & 3000 & 9000 \\
\hline Recycle ratio of FTR & 0.3 & 0.9 & 0.3 & 0.9 & 0.3 & 0.9 & 0.3 & 0.9 \\
\hline Purge split & 0.0 & 0.4 & 0.0 & 0.4 & 0.0 & 0.4 & 0.0 & 0.4 \\
\hline Boiling water to FTR $\left({ }^{\circ} \mathrm{C}\right)$ & 190 & 250 & 190 & 250 & 190 & 250 & 190 & 250 \\
\hline
\end{tabular}

Table 10. Optimizer changes in Hysys when thermal efficiency was used as objective function

\begin{tabular}{ll}
\hline Case & Change from previous \\
\hline TE base case & Based on CE4 but tolerance set to $1 \mathrm{E}-5$ and maximum change per iteration set to 0.1 \\
TE 2 & Lower bounds for reactor volume set to 1500 , while for molar flow oxygen and steam was 3500 and 4500 , penalty for H2/CO ratio set \\
& to 1000 \\
TE 3 & Penalty value increased to 10000 , tolerance set to $1 \mathrm{E}-4$, maximum change per iteration set to 0.2 \\
TE 4 & New start value for steam \\
TE 5 & New bounds for steam was set between 6500 and 11000 , maximum change per iteration set to 0.3 \\
TE 6 & Maximum change per iteration set to 0.3 \\
TE 7 & Maximum change per iteration set to 0.5 \\
Bypass & Liquid from V-101 bypassed V-102 and sent straight to upgrade, penalty value back to 50, tolerance set to $1 \mathrm{E}-5$, maximum change per \\
\hline
\end{tabular}

\section{Results and Discussion}

\subsection{Base Case Evaluation}

With the GTL model set up as shown in Figure 3, an evaluation of the process was conducted to reveal if the process was running as expected and to reveal the potential optimization possibilities.

As stated earlier, the model for the FT reaction is based on the ASF distribution in addition to the methanation reaction. For the ASF distribution a plot of the logarithm of the weight fraction divided by carbon number, against carbon number, is to yield a straight line with the logarithm of $\alpha$ as slope. This is given directly from the mathematical form of the equation and to make sure the reactions were modelled correctly, such a plot was constructed for the base case. The weight fractions were obtained from stream leaving the FTR in the GTL flowsheet and for this purpose the two recycle loops were opened so that the recycle would not affect the distribution. Also as the components $\mathrm{C}_{21}-\mathrm{C}_{30}$ are lumped into one component it was omitted from the plot as this would give a misrepresentation of component $\mathrm{C}_{30}$. Figure 2 shows the plot for the base case and it can be seen that the components with 2-20 carbon atoms in the chain appears to follow a straight line. This shows that the simulation predicts the right outcome of the FT reactions.

As the reaction fundament of the model was confirmed to be correct the performance of the process could be evaluated. Table 11 gives the conditions and compositions of the main stream and there are certain significant features to note.

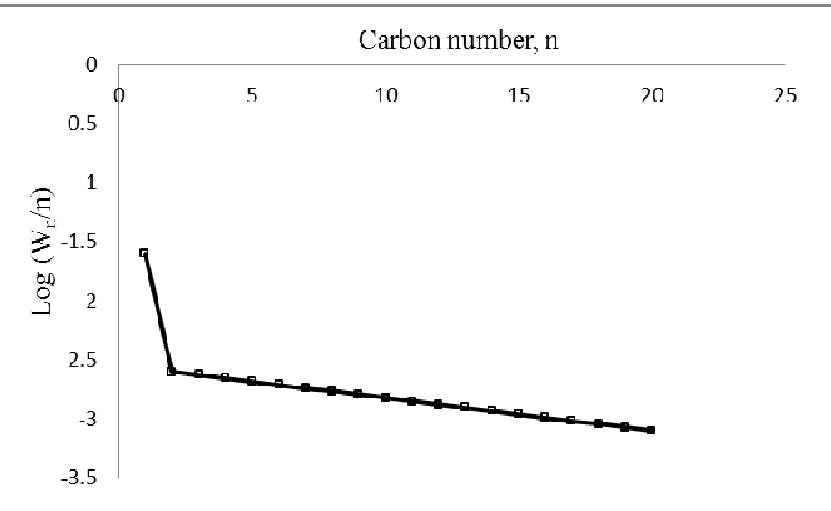

Figure 2. Logarithm of the weight fraction divided by carbon number carbon number (n), for components $C_{l} C_{20}$ in the stream leaving the FTR the GTL flow sheet 


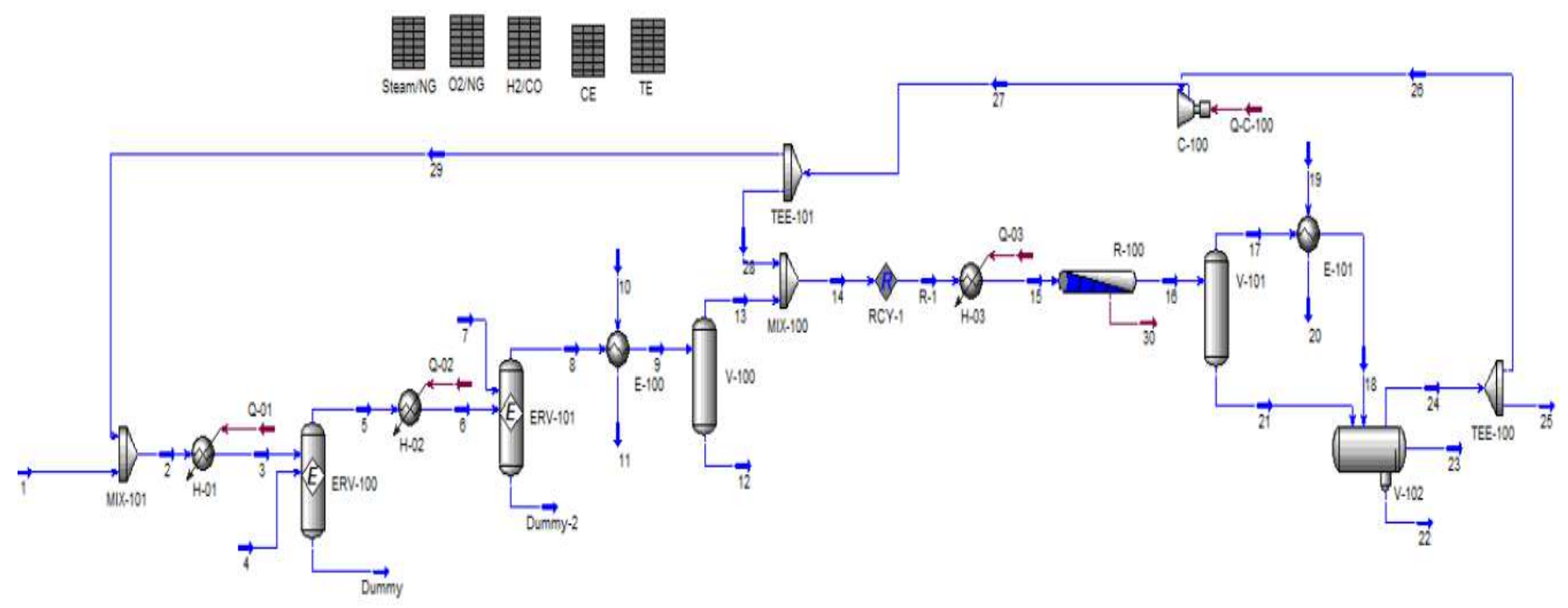

Figure 3. Flowsheet of the simulated GTL plant in Hysys.

Table 11. Stream table of important features and composition in the simulated base case.

\begin{tabular}{|c|c|c|c|c|c|c|c|c|c|c|c|}
\hline \multirow{3}{*}{ Stream } & \multirow{3}{*}{$\mathrm{T}\left({ }^{\mathrm{O}} \mathrm{C}\right)$} & \multirow{3}{*}{ Pressure (kPa) } & \multicolumn{9}{|c|}{ Molar flow (kgmole/hr) } \\
\hline & & & \multirow{2}{*}{ Total } & \multirow{2}{*}{ Pure } & \multirow{2}{*}{ CO } & \multirow{2}{*}{$\mathbf{H}_{2}$} & Light ends & LPG & GTL Naphtha & Diesel & Base Oil \\
\hline & & & & & & & $\mathrm{C}_{1-2}$ & $\mathrm{C}_{3-4}$ & $\mathrm{C}_{5-11}$ & $\mathrm{C}_{12-20}$ & $\mathrm{C}_{21+}$ \\
\hline 1 & 40 & 3000 & 8195 & & - & - & 7892 & 233 & 18 & - & - \\
\hline 2 & 58.64 & 3000 & 13330 & & 1115 & 2764 & 8796 & 314 & 42 & - & - \\
\hline 3 & 455 & 3000 & 13330 & & 1115 & 2764 & 8598 & 274 & 59 & - & - \\
\hline 4 & 252 & 4045 & 5659 & $\mathrm{H}_{2} \mathrm{O}$ & - & - & - & - & - & - & - \\
\hline 5 & 527.3 & 3000 & 18500 & & 123 & 1945 & 9940 & - & 23 & - & - \\
\hline 7 & 200 & 3000 & 4850 & $\mathrm{O}_{2}$ & - & - & - & - & - & - & - \\
\hline 8 & 979.3 & 3000 & 35700 & & 8521 & 18059 & 1163 & - & 23 & - & - \\
\hline 9 & 38 & 3000 & 35700 & & 8521 & 18059 & 1163 & - & 23 & - & - \\
\hline 12 & 38 & 3000 & 6010 & & - & - & - & - & - & - & - \\
\hline 13 & 38 & 2000 & 28756 & & 8521 & 18060 & 1164 & - & 24 & - & - \\
\hline 14 & 58 & 2000 & 45753 & & 13231 & 26250 & 3560 & 135 & 161 & 0.05 & - \\
\hline 15 & 210 & 2000 & 45753 & & 13231 & 26250 & 3560 & 135 & 161 & 0.05 & - \\
\hline 17 & 221.8 & 1940 & 33531 & & 6015 & 10953 & 4580 & 832 & 3282 & 1583 & 0.8 \\
\hline 18 & 38 & 1940 & 33531 & & 6015 & 10953 & 4580 & 1027 & 3282 & 1583 & 0.8 \\
\hline 21 & 221.8 & 1940 & 104 & & 0.68 & 1 & 0.69 & 0.13 & 2 & 27 & 70 \\
\hline 22 & 46.6 & 1940 & 3755 & $\mathrm{H}_{2} \mathrm{O}$ & - & - & - & - & - & - & - \\
\hline 23 & 46.6 & 1940 & 5567 & & - & - & 11 & 613 & 3063 & 1531 & 71 \\
\hline 24 & 46.6 & 1940 & 24325 & & 6015 & 10954 & 4581 & 413 & 222 & 0.17 & - \\
\hline 25 & 46.6 & 1940 & 2188 & & 190 & - & 1460 & 237 & 38 & 0.01 & - \\
\hline 26 & 46.6 & 1940 & 22137 & & 5825 & 10954 & 3120 & 176 & 184 & 0.15 & - \\
\hline 27 & 95.48 & 3000 & 22137 & & 5825 & 10954 & 3120 & 176 & 184 & 0.15 & - \\
\hline 28 & 95.48 & 3000 & 17001 & & 4709 & 8190 & 2396 & 135 & 141 & 0.12 & - \\
\hline 29 & 95.48 & 3000 & 5136 & & 1115 & 2764 & 724 & 40 & 42 & 0.03 & - \\
\hline
\end{tabular}

First, it can be seen from the molar flows of LPG and light ends from stream 2 and 5, that the higher hydrocarbons are almost completely converted to methane in the pre-reformer which is an indication that this unit seems to operate very well.

Second, it is observed that stream 8 has a $\mathrm{H} 2 / \mathrm{CO}$ ratio of 2.119 which is close to the theoretical value of 2.1 . However there is still methane left in the stream indicating, together with the syngas temperature of 979.3, that further potential for the production of syngas is present.

Third, there is still much $\mathrm{H} 2$ and $\mathrm{CO}$ present in the stream leaving the reactor, indicating a low conversion in the reactor, which naturally is undesirable. This is confirmed by Hysys with conversions of 47.98 and $2.64 \%$ for the FT reaction and methanation reaction respectively.

Furthermore, stream 23 shows that the stream going to the upgrading unit mostly consists of GTL naphtha, diesel and base oil and with relatively small amounts of both light ends, LPG, CO and H2. This indicates an effective separation system after the reactor.

For the recycle stream, small amounts of desired products are being recycled and the stream mainly consists of hydrogen, carbon monoxide and methane. However the recycle stream is three times the size of the inlet feed, which is not optimal.

From this evaluation however, it is made clear that parameters such as the $\mathrm{H} 2 / \mathrm{CO}$ ratio, temperature of the syngas, reaction extents in the FTR and the liquid volume of product 
gives important information of the performance of the process. It can also be stated that the process operates as expected, but is nevertheless not at an optimal stage and shows optimization potential in terms of conversion in the FTR.

\subsection{Case Studies}

The result of the case studies conducted is presented and discussed in the following sections. Table 12 shows the main process parameters, variables adjusted in the optimization and the optimization target variables for the various case studies conducted.

\subsubsection{Case 1 - FTR Volume}

The result of the first case study is shown in Figure 4, from the figure it is observed that an optimal reactor volume based on the consumption of reactants seems to be accomplished at about $1600 \mathrm{~m}^{3}$. At this volume however, there is still a small mole flow left of both reactants which is to try and maintain the $\mathrm{H}_{2} / \mathrm{CO}$ ratio at about 2 all through the reactor as this is the desirable ratio for the FT reaction.

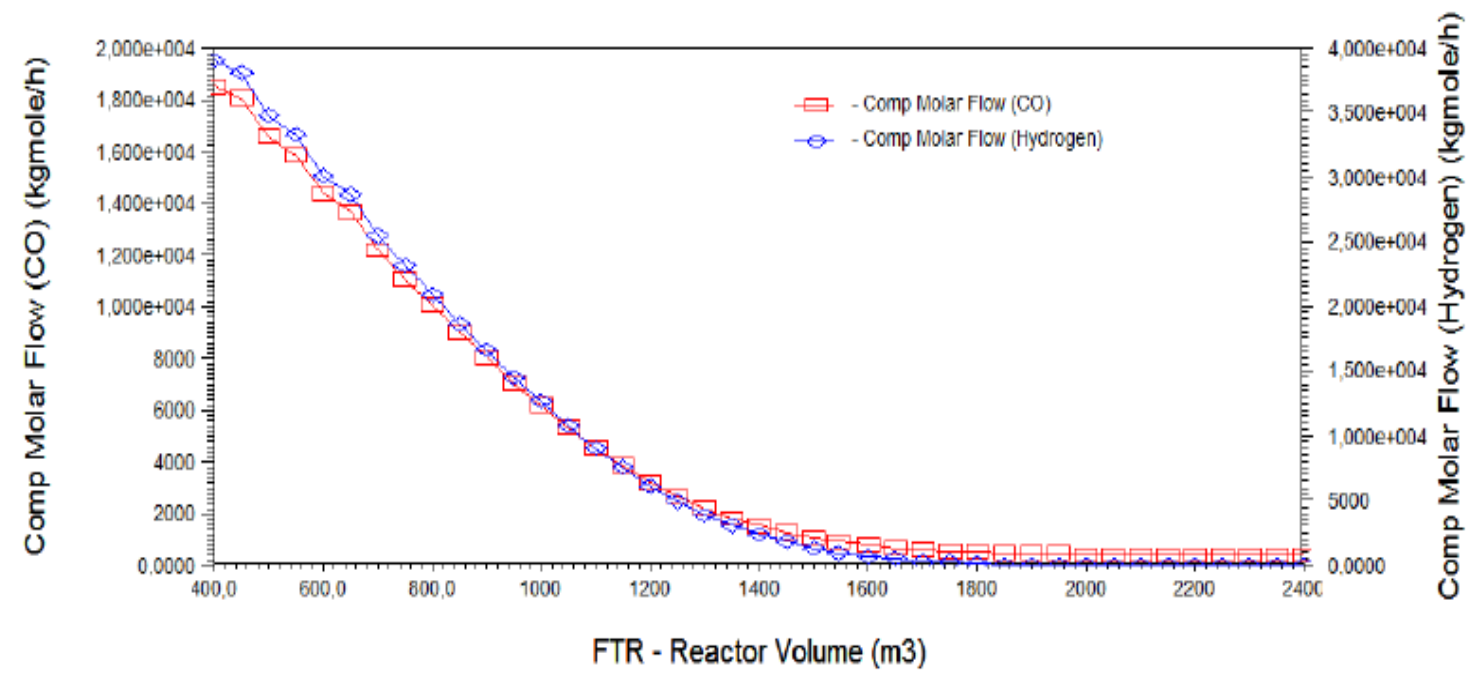

Figure 4. Molar flow of hydrogen, (blue diamonds) and carbon monoxide, (red squares), in (kmol/h), as a function of FTR volume, in $m^{3}$.

Also, it could be pointed out that $\mathrm{H}_{2}$ is used faster than $\mathrm{CO}$ and because of this there will be a point where the ratio will be below 2 and continue to decrease with increasing reactor volume. At this point, increasing the volume would not give more output, only a larger vessel.
The first of the two case study analysis on molar flow of oxygen described earlier, gives an almost linear decrease in $\mathrm{H}_{2} / \mathrm{CO}$ ratio with increasing oxygen. This is shown in Figure 5 and based on this case study the molar flow of oxygen should not exceed $5520 \mathrm{kmol} / \mathrm{h}$ in order to keep the ratio above 2 .

\subsubsection{Case 2 - Molar Flow of Oxygen}

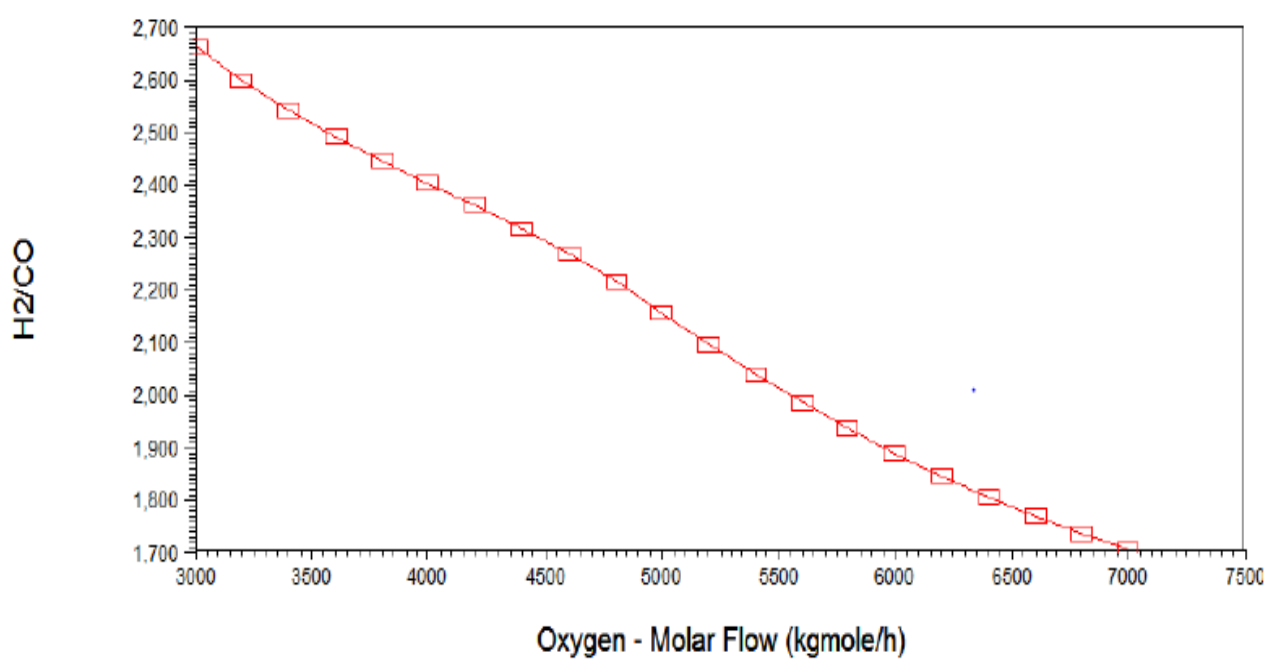

Figure 5. $\mathrm{H}_{2} / \mathrm{CO}$ ratio in the syngas leaving the ATR as a function of molar flow of oxygen in the range $3000-7000 \mathrm{kmol} / \mathrm{h}$, added to the ATR

The latter case study is shown in Figure 6 and it indicates an increasing temperature with increasing oxygen flow as expected. To keep the temperature below $1030{ }^{\circ} \mathrm{C}$ the molar flow should be kept below $4880 \mathrm{kmol} / \mathrm{h}$. Comparing to Figure 5 this would correspond to $\mathrm{H}_{2} / \mathrm{CO}$ ratio of 2.193. The molar flow of oxygen was consequently adjusted to $4870 \mathrm{kmol} / \mathrm{h}$ as 
this satisfied both constraints.

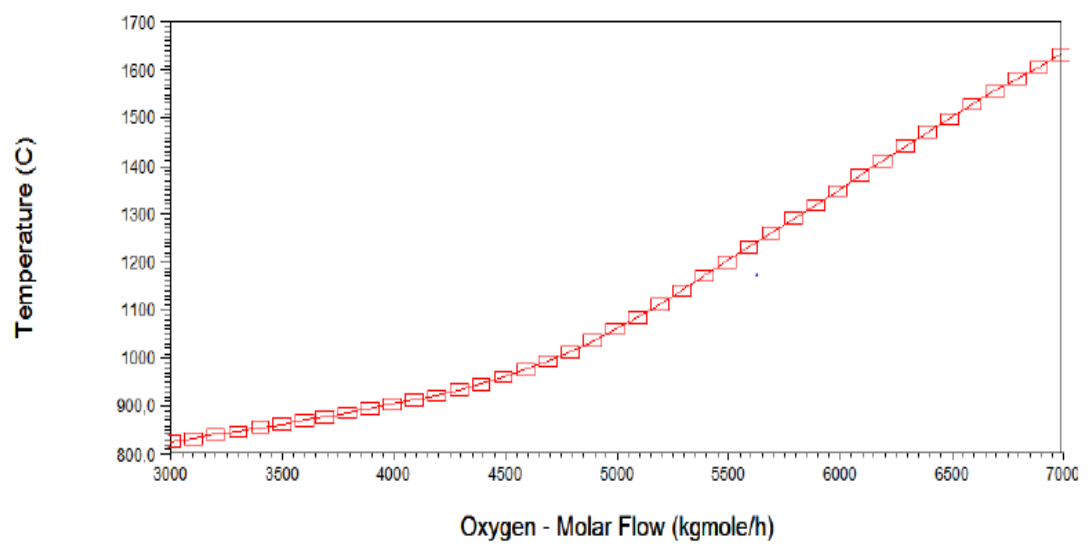

Figure 6. Temperature $\left({ }^{\circ} \mathrm{C}\right)$ of syngas as a function of molar flow of oxygen to the ATR in the range $3000-7000(\mathrm{kmol} / \mathrm{h})$.

\subsubsection{Case 3-Molar Flow of Steam}

The next variable which was optimized was steam and as it can be seen from Figure 7, in order to keep the $\mathrm{H}_{2} / \mathrm{CO}$ ratio above 2 , the molar flow of steam needs to exceed $4500 \mathrm{kmol} / \mathrm{h}$. Not only does the molar flow of steam affects the $\mathrm{H}_{2} / \mathrm{CO}$ ratio, but also the temperature leaving the ATR. Figure 8 shows this relationship and it can be seen that the temperature generally decreases with increased molar flow of steam. To maintain the temperature below $1030^{\circ} \mathrm{C}$ the molar flow of steam should be above $5740 \mathrm{kmol} / \mathrm{h}$. Comparing this value with the $\mathrm{H}_{2} / \mathrm{CO}$ ratio plot gives a ratio of approximately 2.1 , which is above the minimum value of 2 and at the theoretical optimal value from the ASF distribution. The steam molar flow was consequently set to be $5740 \mathrm{kmol} / \mathrm{h}$. From Table 12 it can be seen that this lead to a further small increase in CE, TE and the molar flow of product.

The result is shown in Figure 9 and indicates that the oxygen flow has a much greater effect on the temperature than steam.

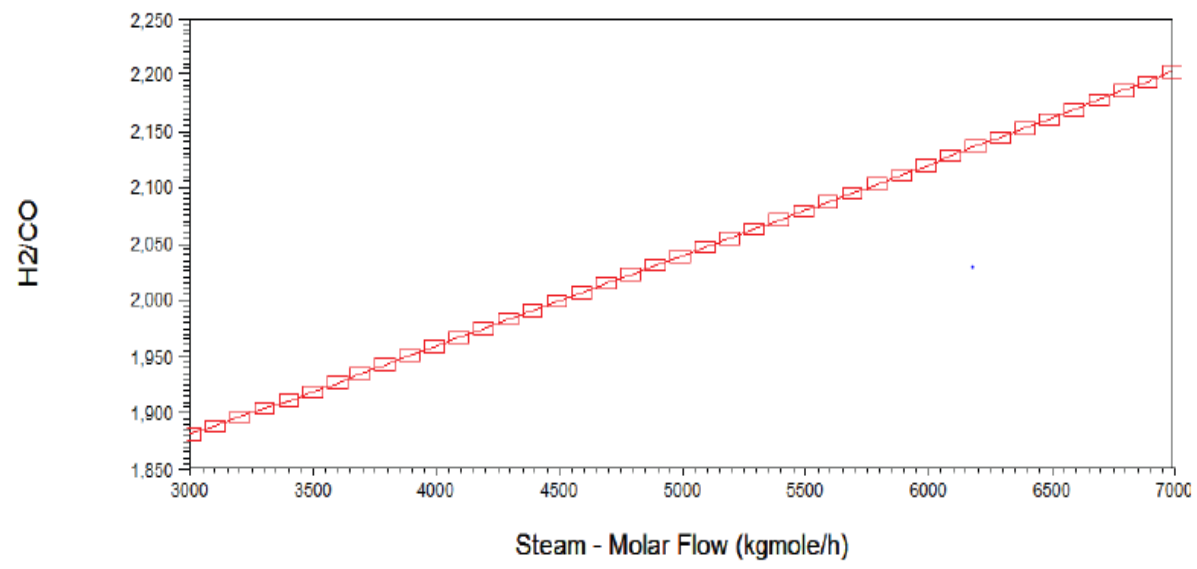

Figure 7. $\mathrm{H}_{2} / \mathrm{CO}$ ratio plotted against molar flow of steam in the range $3000-7000 \mathrm{kmol} / \mathrm{h}$

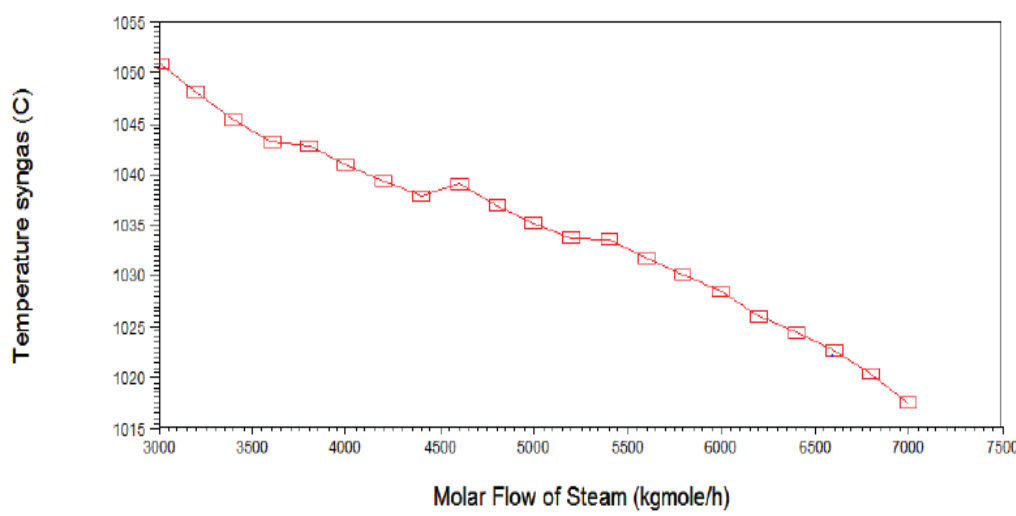

Figure 8. Temperature $\left({ }^{\circ} \mathrm{C}\right.$ ) of syngas leaving the ATR as a function of molar flow of steam in the range 3000-7500 $\mathrm{kmol} / \mathrm{h}$ added to the pre-reformer 


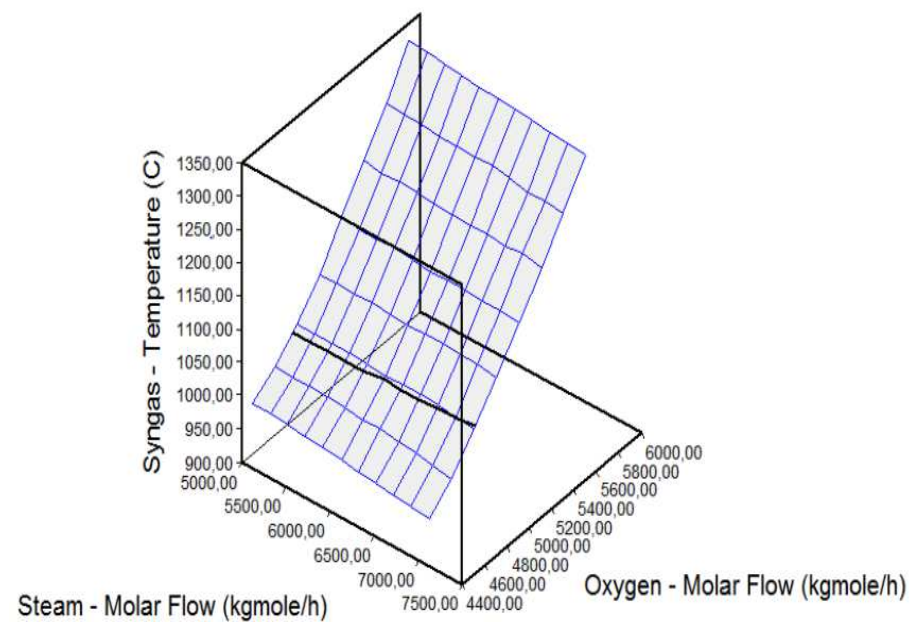

Figure 9. Temperature $\left({ }^{\circ} \mathrm{C}\right)$ of syngas leaving the ATR as a function molar flow of both oxygen and steam in $\mathrm{kmol} / \mathrm{h}$

\subsubsection{Case 4 - Recycle Fraction to FTR}

Figure 10 shows the molar flow to upgrading unit as a function of the recycle ratio back to the FTR. The molar flow to upgrading unit increases with increased recycle as expected as the unconverted components from previous pass through the reactor is now converted. However, at a point the accumulation of higher hydrocarbons will make the recycle decrease the output instead. From the case study it can be seen that a recycle ratio of 0.85 would give the maximum product flow rate. However as can be seen from Table 12 this gave a syngas temperature of $1056^{\circ} \mathrm{C}$. This temperature is above the constraint from a material aspect hence, this process is not an option.

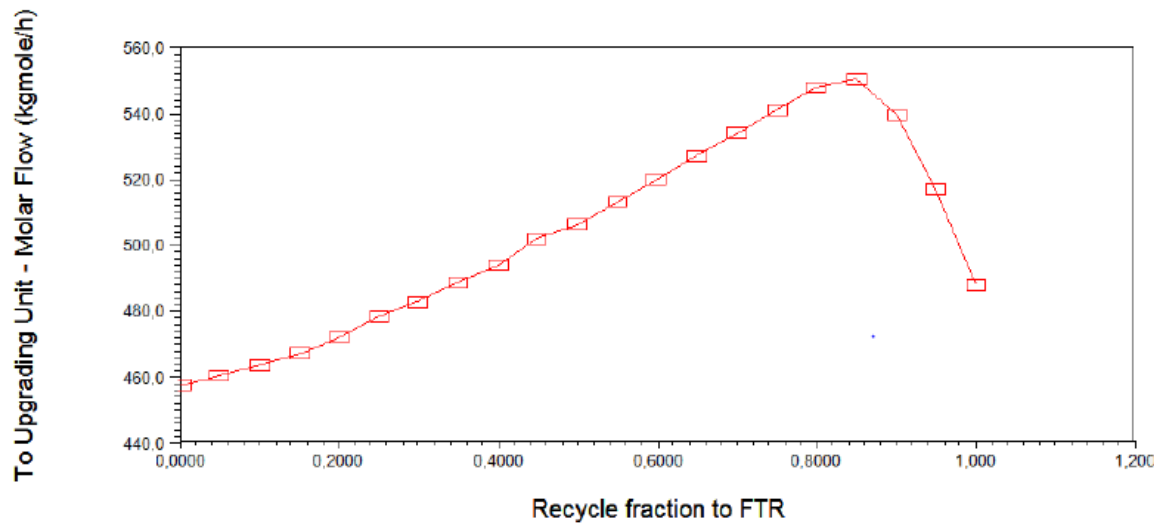

Figure 10. Molar flowrate $(\mathrm{kmol} / \mathrm{h})$ to upgrading unit as a function of recycle fraction back to the FTR

The result for the second case study conducted is now shown in Figure11. The temperature increases linearly with increased recycle which likely is attributed to increase in exothermic conversion of more feeds. From this figure it can be seen that in order to keep the temperature below $1030^{\circ} \mathrm{C}$, the highest recycle ratio possible is 0.768 . This is the same value as used in the base case and previous case studies.

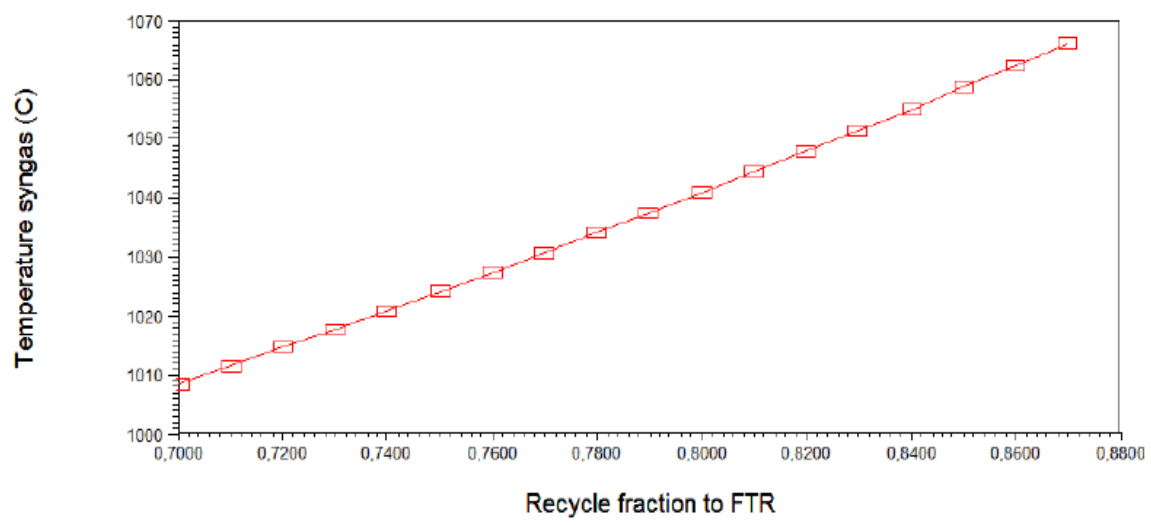

Figure 11. Syngas temperature $\left({ }^{\circ} \mathrm{C}\right)$ as a function of recycle fraction back to the FTR 


\subsubsection{Case $5-\mathrm{H}_{2} / \mathrm{CO}$ Ratio of 2.15}

From Case-3, it was found that a ratio of 2.15 was to be obtained, without exceeding $1030^{\circ} \mathrm{C}$, at approximately 6330 $\mathrm{kmol} / \mathrm{h}$. After some trial and error with values around this, a molar flow of steam at 6310 was found to give a good ratio. From Table 12 it can be seen that this increased ratio gave an improved $\mathrm{CE}$, TE and molar flow to upgrading unit, but not an increase in volume of liquid product.

\subsubsection{Case 6 - Steam and Flow to Upgrading}

The result of case 6 is shown in Figure 12. It can be seen that the maximum molar flow to upgrading unit of $552 \mathrm{kmol} / \mathrm{h}$ is achieved at a $\mathrm{H}_{2} / \mathrm{CO}$ ratio of 2.16 which corresponds to a molar flow rate of steam of $6500 \mathrm{kmol} / \mathrm{h}$. Although it was determined at a previous stage that the flow of steam had a much smaller impact on temperature than oxygen. A high temperature out of the ATR is still desired in relation to maximum conversion and hence the temperature was plotted against the molar flow to upgrading unit and steam. From the plot as shown in Figure 13 it can be seen that this molar flow of steam corresponds to a temperature of about $1023^{\circ} \mathrm{C}$.

As a consequence the steam molar flow was altered to $6500 \mathrm{kmol} / \mathrm{h}$ and then the oxygen flow was adjusted by trial and error to achieve a temperature closer to $1030^{\circ} \mathrm{C}$. This was found to be at an oxygen flow rate of $4900 \mathrm{kmol} / \mathrm{h}$. However adding oxygen to increase the temperature leads to a decrease in $\mathrm{H}_{2} / \mathrm{CO}$ ratio and the resulting ratio obtained in this simulation was 2.155. Both CE, TE flow to upgrading in terms of both molar flow and liquid volume was improved for this simulation as seen in Table 12. This could thus indicate CO ratio leads to improved production. Also the flow of steam, oxygen and the temperature of syngas increased from the previous case and due to the intertwined relationship of these variables it is difficult to point out the determining factor.

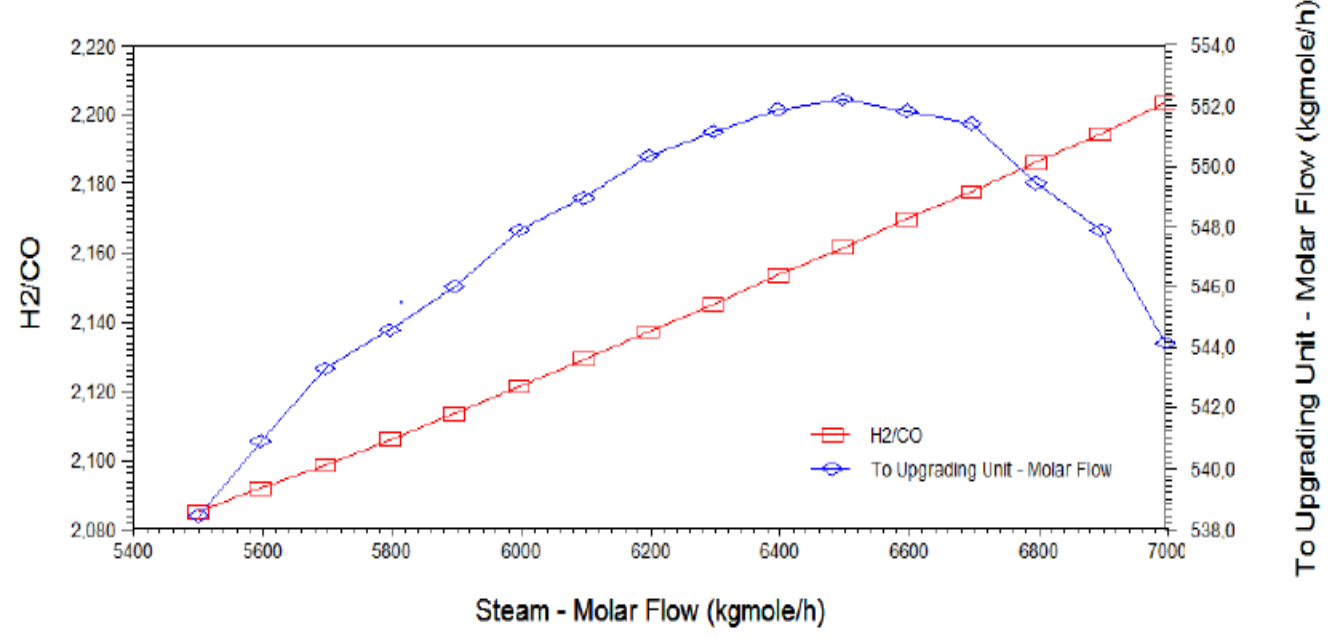

Figure 12. Plot of $\mathrm{H}_{2} / \mathrm{CO}$ ratio and molar flowrate to upgrading unit (kmol/h) as a function of molar flowrate of steam $(\mathrm{kmol} / \mathrm{h})$

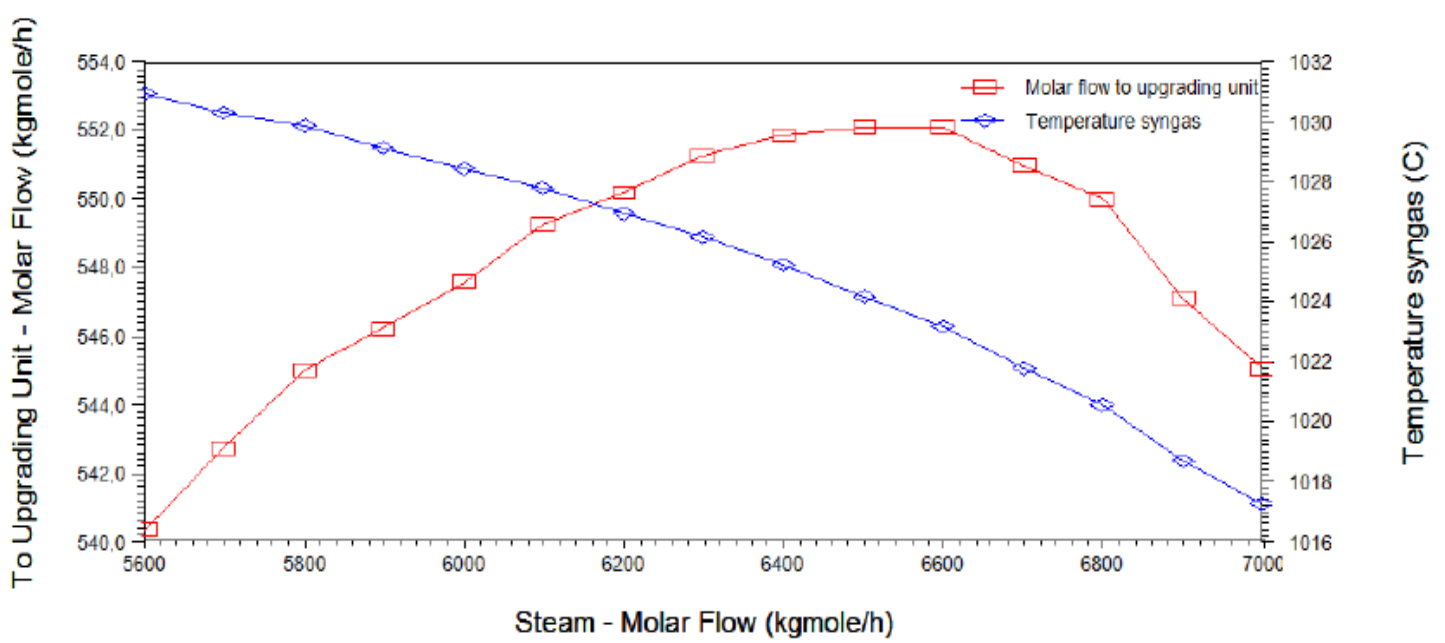

Figure 13. Plot of molar flowrate to upgrading unit $(\mathrm{kmol} / \mathrm{h})$ and temperature of syngas $\left({ }^{O} \mathrm{C}\right)$ as a function of molar flowrate of steam $(\mathrm{kmol} / \mathrm{h})$

\subsubsection{Case 7 - Multi Variable}

The case study analysis gave 7000 and $5000 \mathrm{kmol} / \mathrm{h}$ in molar flow respectively for steam and oxygen as what would give the highest molar flow to upgrading of $558.7 \mathrm{kmol} / \mathrm{h}$, and should give $\mathrm{a}_{2} / \mathrm{CO}$ ratio of 2.147 . Not unexpectedly, when 
considering Figure 9, the temperature obtained was $1058^{\circ} \mathrm{C}$, which is well over the target of $1030^{\circ} \mathrm{C}$. After several trial and error adjusting the flow of oxygen and steam a scenario was found to fulfil the criteria of temperature below $1030^{\circ} \mathrm{C}$ with oxygen flow of $4900 \mathrm{kmol} / \mathrm{h}$ and steam at $6700 \mathrm{kmol} / \mathrm{h}$. The rest of the result variables from this scenario is shown in Table 12 and again an improvement in $\mathrm{CE}, \mathrm{TE}$ and flow to upgrading unit was observed.

Following the introduction of an adjust block, the optimum values were found to be $4914 \mathrm{kmol} / \mathrm{h}$ and $6900 \mathrm{kmol} / \mathrm{h}$ for oxygen and steam respectively, $\mathrm{H}_{2} / \mathrm{CO}$ ratio of 2.174 and an output of $557.1 \mathrm{kmol} / \mathrm{h}$. The rest of simulation parameters are given in Table 12 under Case 7-adjust.

\subsubsection{Case 8 - FTR Volume Revisited}

From the case study it was found that the maximum molar flow to upgrading unit, $566.8 \mathrm{kmol} / \mathrm{h}$, was achieved by a molar flow of steam at $6200 \mathrm{kmol} / \mathrm{h}$, which is much smaller than what was obtained from Case 7 . This was then changed for the simulation and a molar flow to upgrading unit of 568.4 was obtained.

This indicates that as other variables have changed through the range of case studies, the optimized value for steam found in the beginning, no longer was valid as many of the other parameters had changed.

Table 12. Main process parameters, variables adjusted in the optimization and the optimization target variables for the various case studies conducted

\begin{tabular}{|c|c|c|c|c|c|c|c|c|c|c|}
\hline Parameter & Base case & 1 & 2 & 3 & 4 & 5 & 6 & 7 & 7 -adjust & 8 \\
\hline FTR Volume $\left(\mathrm{m}^{3}\right)$ & 1000 & 1600 & 1600 & 1600 & 1600 & 1600 & 1600 & 1600 & 1600 & 2100 \\
\hline \multicolumn{11}{|l|}{ FTR Conversions } \\
\hline FTR (\%) & 47.98 & 86.09 & 84.44 & 85.78 & 90.83 & 90.53 & 91.11 & 90.77 & 91.81 & 93.51 \\
\hline Methanation & 2.64 & 4.78 & 4.59 & 4.75 & 5.69 & 5.56 & 5.74 & 5.66 & 5.96 & 6.51 \\
\hline Syngas Temp., ${ }^{\circ} \mathrm{C}$ & 979.3 & 1028 & 1030 & 1030 & 1056 & 1027 & 1029 & 1027 & 1030 & 1030 \\
\hline \multicolumn{11}{|l|}{ Ratios } \\
\hline $\mathrm{H}_{2} / \mathrm{CO}$ & 2.119 & 2.102 & 2.09 & 2.104 & 2.151 & 2.147 & 2.155 & 2.165 & 2.174 & 2.175 \\
\hline $\mathrm{O}_{2} / \mathrm{NG}$ & 0.5918 & 0.5918 & 0.5943 & 0.5943 & 0.5943 & 0.5943 & 0.5979 & 0.5979 & 0.5996 & 0.5992 \\
\hline Purge fraction & 0.2 & 0.2 & 0.2 & 0.2 & 0.2 & 0.2 & 0.2 & 0.2 & 0.2 & 0.2 \\
\hline Recycle to FTR & 0.768 & 0.768 & 0.768 & 0.768 & 0.85 & 0.768 & 0.768 & 0.768 & 0.768 & 0.768 \\
\hline Recycle to feed & 0.232 & 0.232 & 0.232 & 0.232 & 0.15 & 0.232 & 0.232 & 0.232 & 0.232 & 0.232 \\
\hline CE $(\%)$ & 59.98 & 78.17 & 78.43 & 78.45 & 78.1 & 78.58 & 78.83 & 79.01 & 79.08 & 79.25 \\
\hline TE $(\%)$ & 47.86 & 62.5 & 62.71 & 62.73 & 62.46 & 62.84 & 63.04 & 63.18 & 63.38 & 63.4 \\
\hline \multicolumn{11}{|l|}{ Product molar flow } \\
\hline in std.bbl/d & 14310 & 18820 & 18890 & 18890 & 18830 & 18940 & 19000 & 19040 & 19060 & 19120 \\
\hline
\end{tabular}

\subsection{Optimizer}

\subsubsection{Product Flow Optimization}

From the optimization on molar flow it was observed that an increase in the molar flow does not always lead to an increase in the liquid volume flow when compared to previous cases. However, the same was also experienced when the objective function was changed to liquid volume. It was further also observed for all objective functions that the best result in liquid volume never occurred at the same optimizer run as the best result in molar flow. This is most likely attributed to the fact that the molar flow only measures the total size of the stream and does not take into consideration variations in composition, while the liquid volume is dependent of the density and molar mass of the stream and because of this two identically molar flows can give two totally different volumes based on composition.

Table 13 however shows the results of the optimizer applied to product flow to the upgrading unit. From the table, it can be seen that Case 10 shows the best results in terms of CE, TE and liquid volume flow to upgrading unit and are highlighted in red. The highest molar flow is however found for case 9 and is highlighted in blue. It can also be seen that Case 11 has the second highest values for the three same parameters as Case 10. Comparing them to see if there are any trends indicating what will result in a high production ratio, they have the same oxygen to carbon ratio, almost same purge fractions and the two smallest $\mathrm{H}_{2} / \mathrm{CO}$ ratios, close to 2.0. The steam to carbon ratio is however not that similar and might thus not be the most important factor for liquid production.

First investigating the purge fraction, it can be seen that Case 6 and 7 have the same purge fraction as case 10 and gives only slighter smaller molar flow to upgrading, but have lower liquid volume to upgrading unit values. By further comparison it is also seen that Case 6 and 7 have lower oxygen to carbon ratios, and higher $\mathrm{H}_{2} / \mathrm{CO}$ ratios at about 2.13 than Case 10 and 11 . Thus purge fraction alone is likely not the decisive factor. However, Case 6 and 7 have about same steam to carbon ratio as Case 10 and as previously mentioned these three cases are most similar in terms of molar flow to upgrading unit and this could indicate that the steam added mostly affects the molar flow and not liquid flow to upgrading.

Next, it can be seen that the base case has a low $\mathrm{H}_{2} / \mathrm{CO}$ ratio similar to Case 10 and 11; however it gives poorer optimization values indicating that neither $\mathrm{H}_{2} / \mathrm{CO}$ ratio alone dictates the optimum. Finally the oxygen to carbon ratio was found to be comparably smaller for all other cases, but came closest for case 4. As for the base case however the optimization values are lower than for case 10 and 11 indicating that this probably is not the decisive factor either.

From this brief evaluation it appears as though there is not one factor alone dictating the optimum process, but rather a 
combination of factors is needed to yield a positive outcome.

Table 13. Results of the Optimizer applied to flow to upgrading unit in terms of the process performance indicators and optimization targets chosen for the simulations in this work

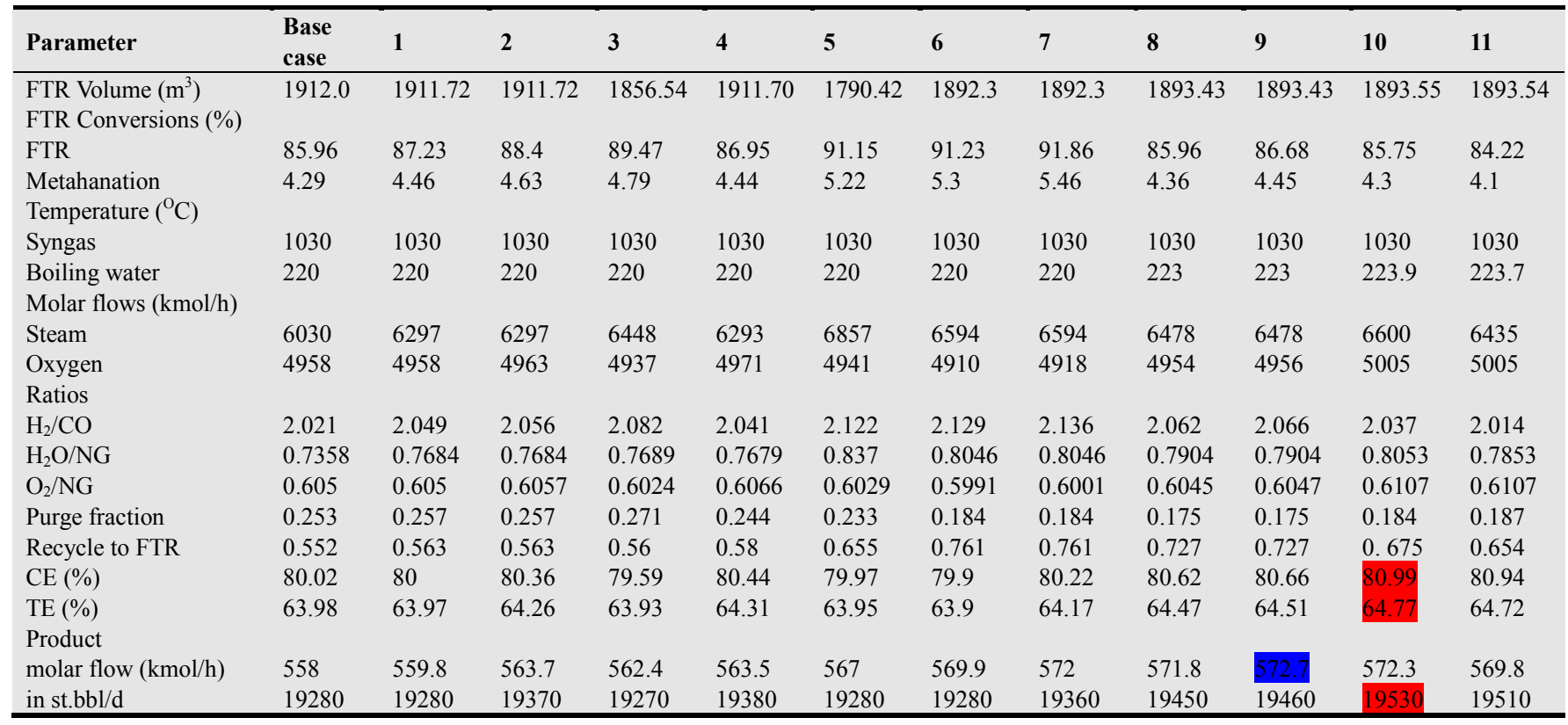

\subsubsection{Carbon Efficiency Optimization}

From Table 14 it can be seen that Case CE2 have the best $\mathrm{CE}, \mathrm{TE}$ and liquid volume flow to upgrading unit and is highlighted in red. However, while the optimizer was applied to the product flow the highest molar flow value to upgrading unit was found at a different case than the three other parameters. For this part Case CE3 was found to perform best for the molar flow and is highlighted in blue.

It can also be seen that the low $\mathrm{H}_{2} / \mathrm{CO}$ ratio as was observed to give good results from the product flow optimization is present at all four CE optimizations and that they all have comparable product flows as the Case 10 and 11 from the previous optimizer. The oxygen to carbon ratio is also at about 0.61 for the three last optimizations on $\mathrm{CE}$, which was also observed for Case 10 and 11 from the product flow optimizer. Finally the purge ratio for CE2, CE3 and CE4 is equal and the same as for Case 11 and almost same as Case 10. These three cases have slightly higher liquid volumes than the base case for $\mathrm{CE}$ indicating that the combination of a low $\mathrm{H}_{2} / \mathrm{CO}$ ratio, oxygen to carbon ratio at about 0.61 and a purge ratio at about 0.187 is beneficial for the process.

Comparing the results from this optimization with the optimization on flow to upgrading unit shows an increase in all target variables applied to the simulation.

Table 14. Results of the optimizer applied to carbon efficiency in terms of the process performance indicators and optimization targets chosen for the simulations in this work

\begin{tabular}{|c|c|c|c|c|}
\hline Parameter & CE base case & CE2 & CE3 & CE4 \\
\hline FTR Volume $\left(\mathrm{m}^{3}\right)$ & 1933.523 & 1933.523 & 1933.33 & 1893.33 \\
\hline \multicolumn{5}{|l|}{ FTR conversions $(\%)$} \\
\hline FTR & 85.93 & 82.17 & 85.19 & 85.06 \\
\hline Methanation & 4.3 & 3.86 & 4.23 & 4.21 \\
\hline Temperature syngas $\left({ }^{\circ} \mathrm{C}\right)$ & 1030 & 1030 & 1030 & 1030 \\
\hline \multicolumn{5}{|l|}{ Molar flows $(\mathrm{kmol} / \mathrm{h})$} \\
\hline Steam & 6435 & 6435 & 6900 & 6600 \\
\hline Oxygen & 4967 & 5027 & 5032 & 5021 \\
\hline \multicolumn{5}{|l|}{ Ratios } \\
\hline $\mathrm{H}_{2} / \mathrm{CO}$ & 2.044 & 1.993 & 2.03 & 2.022 \\
\hline $\mathrm{H}_{2} \mathrm{O} / \mathrm{NG}$ & 0.7853 & 0.7853 & 0.8419 & 0.8054 \\
\hline $\mathrm{O}_{2} / \mathrm{NG}$ & 0.6061 & 0.6134 & 0.6141 & 0.6126 \\
\hline Purge fraction & 0.207 & 0.187 & 0.187 & 0.187 \\
\hline Recycle to FTR & 0.654 & 0.654 & 0.654 & 0.654 \\
\hline CE (\%) & 80.7 & 81.24 & 81.05 & 81.06 \\
\hline TE $(\%)$ & 64.53 & 64.96 & 64.81 & 64.81 \\
\hline \multicolumn{5}{|l|}{ Product } \\
\hline molar flowrate $(\mathrm{kmol} / \mathrm{h})$ & 568.5 & 570.3 & 572. & 571.4 \\
\hline in st.bbl/d & 19450 & 19580 & 19540 & 19540 \\
\hline
\end{tabular}




\subsubsection{Thermal Efficiency Optimization}

From Table 15 it can be seen that the best results in terms of $\mathrm{CE}, \mathrm{TE}$, molar flow and liquid flow to the upgrading unit, is obtained in the bypass case and is highlighted in green. As explained in Table 10, the liquid product from the FTR is now bypassing the 3-way separator. The liquid product from the FTR will have the same temperature as the reactor at about $223^{\circ} \mathrm{C}$ while the gaseous product from the FTR is cooled to $38^{\circ} \mathrm{C}$ before entering the 3 -way separator. This is done to be able to separate out water and more efficiently separate the light ends for recycling. However with the liquid FTR product previously also passing through the 3-way separator the temperature increases significantly and hence the separation of both water and light ends becomes poorer as the water might evaporate and blend in with both flow to upgrading unit and recycling of light ends. There might also be some of the heavier hydrocarbons that have left the FTR with the gases and the entire point of cooling and passing it through the 3-way separator to recover them diminishes as the liquid product is also passed through this separator. It is therefore not surprising that this simulation appears to be in a class of its own in terms of performance.

From table 15 it can also be seen that there is little change in the optimization variables from case to case and that all result in very good values for the optimization targets. Compared to the optimizers applied previously the obtained results are also better. Further, when comparing the simulations with the previous optimizers it can be seen that also here a low $\mathrm{H}_{2} / \mathrm{CO}$ rate close to 2.0 is present, the oxygen to carbon ratio is slightly higher and around $0.62-0.63$ against previously 0.61 , and the purge fraction previously about 0.187 is now at 0.173 . However, the steam to carbon ratio is much higher and is here above 1 . As previously indicated this variable might affect the molar flow most and as the obtained results are very good, this is further emphasized.

Table 15. Results of the Optimizer applied to flow to thermal efficiency in terms of the process performance indicators and optimization targets chosen for the simulations in this work

\begin{tabular}{|c|c|c|c|c|c|c|c|c|}
\hline Parameter & TE base case & TE2 & TE3 & TE4 & TE5 & TE6 & TE7 & Bypass \\
\hline FTR Volume $\left(\mathrm{m}^{3}\right)$ & 1933.331 & 1933.331 & 1933.331 & 1933.331 & 1933.331 & 1933.331 & 1933.331 & 1933.36 \\
\hline \multicolumn{9}{|l|}{ FTR conversions $(\%)$} \\
\hline FTR & 85.62 & 79.4 & 78.89 & 83.29 & 87.32 & 88.39 & 86.64 & 89.8 \\
\hline Metahanation & 4.29 & 3.58 & 3.52 & 4 & 4.53 & 4.69 & 4.42 & 4.89 \\
\hline Temperature syngas $\left[{ }^{\circ} \mathrm{C}\right]$ & 1030 & 1030 & 1030 & 1030 & 1030 & 1030 & 1030 & 1030 \\
\hline \multicolumn{9}{|l|}{ Molar flowrates $(\mathrm{kmol} / \mathrm{h})$} \\
\hline Oxygen & 5137 & 5105 & 5110 & 5136 & 5154 & 5144 & 5176 & 5089 \\
\hline \multicolumn{9}{|l|}{ Ratios } \\
\hline $\mathrm{H}_{2} / \mathrm{CO}$ & 2.03 & 1.944 & 1.937 & 2.002 & 2.052 & 2.063 & 2.03 & 2.086 \\
\hline $\mathrm{H}_{2} \mathrm{O} / \mathrm{NG}$ & 1.013 & 0.8542 & 0.8542 & 0.9762 & 1.068 & 1.068 & 1.068 & 1.008 \\
\hline $\mathrm{O}_{2} / \mathrm{NG}$ & 0.6268 & 0.6229 & 0.6235 & 0.6267 & 0.6289 & 0.6277 & 0.6316 & 0.621 \\
\hline Purge fraction & 0.173 & 0.173 & 0.173 & 0.173 & 0.173 & 0.173 & 0.173 & 0.19 \\
\hline Recycle to FTR & 0.608 & 0.608 & 0.608 & 0.608 & 0.608 & 0.608 & 0.578 & 0.607 \\
\hline TE $(\%)$ & 65.36 & 64.7 & 65.13 & 65.15 & 65.26 & 65.18 & 65.34 & 65.93 \\
\hline \multicolumn{9}{|l|}{ Product } \\
\hline molar flow $(\mathrm{kmol} / \mathrm{h})$ & 568.5 & 570.3 & 572.6 & 571.4 & 583.6 & 0. & 582.7 & 604.3 \\
\hline in st.bbl/d & 19720 & 19500 & 19630 & 19650 & 19690 & 19670 & 19710 & 19940 \\
\hline
\end{tabular}

Table 16 shows the overall best result in terms of all three optimization targets and as it can be observed, the optimization on TE with bypassing of the liquid product from the FTR in regards to the 3-way separator gave the best result but when omitting the bypass simulation from the optimizer comparison the TE base case becomes the best case from the use of the Hysys Optimizer.
When comparing the results to $\mathrm{CE}$ and $\mathrm{TE}$ benchmarks normally obtained for the GTL process of $77 \%$ and $60 \%$ respectively, it indicates a high degree of optimization of the process [14]. However the simulations in this work do not take into account the upgrading unit and hence these values might have decreased if that was to be included and this should be kept in mind.

Table 16. Summary of the best results for each of the Optimizer objective functions

\begin{tabular}{|c|c|c|c|c|c|}
\hline \multirow{2}{*}{ Objective function } & \multirow{2}{*}{ Case name } & \multirow{2}{*}{ CE $(\%)$} & \multirow{2}{*}{ TE (\%) } & \multicolumn{2}{|c|}{ Flow to upgrading unit } \\
\hline & & & & $(\mathrm{kmol} / \mathrm{h})$ & std.bbl/d \\
\hline Flow to upgrading unit & 10 & 80.99 & 64.77 & 527.3 & 19530 \\
\hline $\mathrm{CE}$ & CE 2 & 81.24 & 64.96 & 570.3 & 19580 \\
\hline \multirow[t]{2}{*}{$\mathrm{TE}$} & TE base case & 81.75 & 65.36 & 568.5 & 19720 \\
\hline & Bypass & 82.41 & 65.93 & 604.3 & 19940 \\
\hline
\end{tabular}


Nevertheless, a GTL plant was simulated with the exclusion of the upgrading unit [14], but with a $\mathrm{CO}_{2}$ removal unit, and comparing efficiencies, the numbers for the work in this report is generally $10-15$ percentage points higher than reported in [14], which is strengthening the indication of a good optimization.

Another indicator for whether or not the optimization has been successful is the liquid volume of products to the upgrading unit. The feed applied was designed for a 17000 $\mathrm{bbl} / \mathrm{d}$ train and from the optimization this is in the range 19700-19940 for the best cases. This further emphasizes the indication of a good optimization.

\section{Conclusion}

A gas to liquids process (GTL) has been simulated and optimized. The parameter study conducted through the use of case studies was found to give good insight into parameter connectivity. The use of Optimizer in Hysys indicated that the choice of objective function between $\mathrm{CE}$, TE and liquid flow to upgrading was irrelevant as optimization of one also optimized the two others. The molar flow to upgrading however did not display maximum values for the same simulations as the three other variables and was found to be a poorer choice of objective function. A continued increase in $\mathrm{CE}, \mathrm{TE}$ and liquid flow to upgrading was observed with the use of Optimizer, however the best result was achieved with a change in flow sheet structure, bypassing the liquid product from the FTR in regards to the 3-way separator. This resulted in a CE of $82.41 \%$, TE of $65.93 \%$ and a production of 19940 $\mathrm{bbl} / \mathrm{d}$ of syncrude. These are more improved results compared to the conventional efficiencies for GTL of $77 \%$ and $60 \%$ respectively.

\section{Appendix A}

Modelling of Fischer-Tropsch reaction in Hysys

The Fischer-Tropsch synthesis was modelled as given by the ASF distribution. Only paraffins were considered in this work and, $\alpha$ was assumed to be 0.9 . All of the components below carbon number 21 was modelled as individual units, while the components with carbon number from 21-30 was lumped in a component designated $\mathrm{C}_{21+}$. The stoichiometric coefficients were calculated after Equation A.1 and A.2 as was outlined in a paper on ASF modelling [17].

$$
\begin{array}{ll}
\mathrm{r}_{\mathrm{FT}}=(1-\alpha)^{2} \alpha^{(\mathrm{i}-1)} & \text { for } \mathrm{C}_{\mathrm{i}}, \mathrm{i}=1, \ldots \mathrm{n} \\
\mathrm{r}_{\mathrm{FT}}=(1-\alpha) \alpha^{20} & \text { for } \mathrm{C}_{[\mathrm{N}+1,1, \infty]}
\end{array}
$$

Table A.1 shows the calculated stoichiometric coefficients used in the Hysys simulations. The lumped component $\mathrm{C}_{21_{+}}$is modelled as $\mathrm{C}_{30} \mathrm{H}_{62}$ due to similar properties. With the coefficients from Table A.1 the full FT reaction can be written as displayed in Equation A.3

$$
\begin{array}{r}
\mathrm{CO}+\mathrm{UH}_{2} \rightarrow 0.01 \mathrm{CH}_{4}+0.009 \mathrm{C}_{2} \mathrm{H}_{6}+0.008 \mathrm{C}_{3} \mathrm{H}_{8}+0.007 \mathrm{C}_{4} \mathrm{H}_{10}+0.007 \mathrm{C}_{5} \mathrm{H}_{12}+0.006 \mathrm{C}_{6} \mathrm{H}_{14}+0.005 \mathrm{C}_{7} \mathrm{H}_{16}+0.005 \mathrm{C}_{8} \mathrm{H}_{18}+ \\
0.004 \mathrm{C}_{9} \mathrm{H}_{20}+0.004 \mathrm{C}_{10} \mathrm{H}_{22}+0.003 \mathrm{C}_{11} \mathrm{H}_{24}+0.003 \mathrm{C}_{12} \mathrm{H}_{26}+0.003 \mathrm{C}_{13} \mathrm{H}_{28}+0.003 \mathrm{C}_{14} \mathrm{H}_{30}+0.002 \mathrm{C}_{15} \mathrm{H}_{32}+0.002 \mathrm{C}_{16} \mathrm{H}_{34}+ \\
0.002 \mathrm{C}_{17} \mathrm{H}_{36}+0.002 \mathrm{C}_{18} \mathrm{H}_{38}+0.002 \mathrm{C}_{19} \mathrm{H}_{40}+0.001 \mathrm{C}_{20} \mathrm{H}_{42}+0.012 \mathrm{C}_{30} \mathrm{H}_{62}+\mathrm{H}_{2} \mathrm{O}
\end{array}
$$

Table A.1. Stoichiometric coefficients used to model the Fischer-Tropsch synthesis in Hysys as calculated by Equation A.1 and A.2. The molar mass for each component was found in the component library of the simulation in Hysys.

\begin{tabular}{lll}
\hline Component & Mole weight [g/mole] & Stoichiometric coefficient \\
\hline $\mathrm{CO}$ & 28.011 & -1.000 \\
$\mathrm{H}_{2}$ & 2.016 & -2.100 \\
$\mathrm{H}_{2} \mathrm{O}$ & 18.015 & 1.000 \\
$\mathrm{CH}_{4}$ & 16.043 & 0.010 \\
$\mathrm{C}_{2} \mathrm{H}_{6}$ & 30.070 & 0.009 \\
$\mathrm{C}_{3} \mathrm{H}_{8}$ & 44.097 & 0.008 \\
$\mathrm{C}_{4} \mathrm{H}_{10}$ & 58.124 & 0.007 \\
$\mathrm{C}_{5} \mathrm{H}_{12}$ & 72.151 & 0.007 \\
$\mathrm{C}_{6} \mathrm{H}_{14}$ & 86.178 & 0.006 \\
$\mathrm{C}_{7} \mathrm{H}_{16}$ & 100.205 & 0.005 \\
$\mathrm{C}_{8} \mathrm{H}_{18}$ & 114.232 & 0.005 \\
$\mathrm{C}_{9} \mathrm{H}_{20}$ & 128.259 & 0.004 \\
$\mathrm{C}_{10} \mathrm{H}_{22}$ & 142.285 & 0.004 \\
$\mathrm{C}_{11} \mathrm{H}_{24}$ & 156.313 & 0.003 \\
$\mathrm{C}_{12} \mathrm{H}_{26}$ & 170.339 & 0.003 \\
$\mathrm{C}_{13} \mathrm{H}_{28}$ & 184.367 & 0.003 \\
$\mathrm{C}_{14} \mathrm{H}_{30}$ & 198.380 & 0.003 \\
$\mathrm{C}_{15} \mathrm{H}_{32}$ & 212.410 & 0.002 \\
$\mathrm{C}_{16} \mathrm{H}_{34}$ & 226.429 & 0.002 \\
$\mathrm{C}_{17} \mathrm{H}_{36}$ & 240.457 & 0.002 \\
$\mathrm{C}_{18} \mathrm{H}_{38}$ & 254.479 & 0.002 \\
$\mathrm{C}_{19} \mathrm{H}_{40}$ & 268.510 & 0.002 \\
$\mathrm{C}_{20} \mathrm{H}_{42}$ & 282.540 & 0.001 \\
$\mathrm{C}_{30} \mathrm{H}_{62}$ & 422.799 & 0.012 \\
\hline
\end{tabular}




\section{References}

[1] M. Nyarko, "Process Plant of Gas to Liquid (GTL): Theory and Simulation"; Lap Lambert Academic Publishing, Ghana, 2012, pp 81-83.

[2] H. K. Yong, K. Jun, J. Hyunku, H. Chonghun, Kyu Song “A simulation study on gas-to-liquid (natural gas to fischer.tropsch synthetic fuel) process optimization"; Chemical Engineering Journal, Vol. 155, pp 427 - 432, 2009.

[3] Mark E Dry, "The fischer tropsch process: 1950-2000," Catalysis Today, vol 71, 2002, pp $227-241$.

[4] M. Panahi, A. Rafiee, S. Stogestad, H. Magne, "A natural gas to liquid process model for optimal operation," Industrial \& Engineering Chemistry Research, Vol. 51, 2012, pp 425-433.

[5] B. Bao, M. E. Mahmoud, O. E. Nimir, "Simulation, integration, and economic analysis of gas-to-liquid processes," Fuel Processing Technology, Vol. 91, 2010, pp703 - 713.

[6] X. Hao, M. Djatmiko, "Simulation analysis of a gtl process using aspen plus," Chemical Engineering Technology, Vol. 31, 2008, pp188-196.

[7] Subhasish Mitra "Gas To Liquid Technology - A Simulation Case Study in Hysis with heat integration" unpublished

[8] A. W. David, N. Chikezie, F. T. Brian, "Gas-to-liquids (gtl): A review of an industry offering several routes for monetizing natural gas," Journal of Natural Gas Science and Engineering, Vol. 9, 2012, pp $196-208$.
[9] J. G. Speight, "Handbook of Industrial Hydrocarbon Processes," Gulf Professional Publishing, Boston, 2011, pp 281 - 323.

[10] R. Guettel, U. Kunz, T. Turek, "Reactors for fischer-tropsch synthesis," Chemical Engineering \& Technology, Vol. 31, pp746-754, 2008.

[11] H. Alfadala, G. V. Rex Reklaitis, M. M. El-Halwagi, "Shell GTL, from Bench scale to World scale," Proceedings of the 1st annual Gas Processing Symposium, 2009, pp378-386.

[12] H. Kevin, "Oryx gtl - a case study," pp 34-36, 2006

[13] M. Nel, "Gtl - a window of opportunity," http://www.sasol.com/sites/default/files/presentations/downloa ds/GTL_A_Window_Opportunity_XTLConference_London_ 7\%2520June2011_1308044026713.pdf, 2011

[14] Ahmad Rafiee. Optimal design issues of a gas-to-liquid process. $\mathrm{PhD}$ thesis, Norwegian University of Science and Technology, 2012.

[15] Haldor Tops Ã̈̈e, "Prereforming catalyst," http://www.topsoe.com/business_areas/synthesis_gas/\%/media/ PDF\%20files/Prereforming/Topsoe_\%20prereforming\%20_ca t_\%20brochure.ashx.

[16] M. Panahi, S. Skogestad, R. Yelchuru, "Steady state simulation for optimal design and operation of a gtl process," Proceedings of the 2nd Annual Gas Processing Symposium, 2010, pp $275-$ 285 .

[17] M. Hillestad, "Modelling the fischer-tropsch product distribution and model implementation," Unpublished, 2011. 